University of Nebraska - Lincoln

DigitalCommons@University of Nebraska - Lincoln

Publications, Agencies and Staff of the U.S.

Department of Commerce

U.S. Department of Commerce

2012

\title{
Land Surface Temperature product validation using NOAA's surface climate observation networks-Scaling methodology for the Visible Infrared Imager Radiometer Suite (VIIRS)
}

\author{
Pierre C. Guillevic \\ Cooperative Institute for Climate and Satellites (CICS), pierre.guillevic@noaa.gov \\ Jeffrey L. Privette \\ NOAA's National Climatic Data Center (NCDC) \\ Benoit Coudert \\ Centre d'Etudes Spatiales de la Biosphère \\ Michael A. Palecki \\ NOAA's National Climatic Data Center (NCDC) \\ Jerome Demarty \\ Institut de Recherche pour le Développement (IRD) \\ See next page for additional authors \\ Follow this and additional works at: https://digitalcommons.unl.edu/usdeptcommercepub \\ Part of the Environmental Sciences Commons
}

Guillevic, Pierre C.; Privette, Jeffrey L.; Coudert, Benoit; Palecki, Michael A.; Demarty, Jerome; Ottlé, Catherine; and Augustine, John A., "Land Surface Temperature product validation using NOAA's surface climate observation networks-Scaling methodology for the Visible Infrared Imager Radiometer Suite (VIIRS)" (2012). Publications, Agencies and Staff of the U.S. Department of Commerce. 381.

https://digitalcommons.unl.edu/usdeptcommercepub/381

This Article is brought to you for free and open access by the U.S. Department of Commerce at DigitalCommons@University of Nebraska - Lincoln. It has been accepted for inclusion in Publications, Agencies and Staff of the U.S. Department of Commerce by an authorized administrator of DigitalCommons@University of Nebraska - Lincoln. 


\section{Authors}

Pierre C. Guillevic, Jeffrey L. Privette, Benoit Coudert, Michael A. Palecki, Jerome Demarty, Catherine Ottlé, and John A. Augustine 


\title{
Land Surface Temperature product validation using NOAA's surface climate observation networks-Scaling methodology for the Visible Infrared Imager Radiometer Suite (VIIRS)
}

\author{
Pierre C. Guillevic ${ }^{\mathrm{a}, \mathrm{b}, *}$, Jeffrey L. Privette ${ }^{\mathrm{b}}$, Benoit Coudert ${ }^{\mathrm{c}}$, Michael A. Palecki ${ }^{\mathrm{b}}$, Jerome Demarty ${ }^{\mathrm{d}}$, \\ Catherine Ottlé ${ }^{\mathrm{e}}$, John A. Augustine ${ }^{\mathrm{f}}$ \\ a Cooperative Institute for Climate and Satellites (CICS), North Carolina State University (NCSU), 151 Patton Avenue, Asheville, NC 28801, USA \\ ${ }^{b}$ NOAA's National Climatic Data Center (NCDC), 151 Patton Avenue, Asheville, NC 28801, USA \\ c Centre d'Etudes Spatiales de la Biosphère (CESBIO), 18 avenue Edouard Belin, 31401 Toulouse, France \\ ' Institut de Recherche pour le Développement (IRD), HydroSciences, 34095 Montpellier, France \\ e Laboratoire des Sciences du Climat et de l'Environnement (LSCE) - IPSL, CNRS-CEA-UVSQ 91191 Gif-sur-Yvette, France \\ ${ }^{f}$ NOAA's Earth System Research Laboratory (ESRL), 325 Broadway, Boulder, CO 80305, USA
}

\section{A R T I C L E I N F O}

\section{Article history:}

Received 6 January 2012

Received in revised form 1 May 2012

Accepted 5 May 2012

Available online 15 June 2012

\section{Keywords:}

Land Surface Temperature

Validation

NPP VIIRS

MODIS

Field experiment

Scaling problem

\begin{abstract}
A B S T R A C T
NOAA will soon use the new Visible Infrared Imager Radiometer Suite (VIIRS) on the Joint Polar Satellite System (JPSS) as its primary polar-orbiting satellite imager. Employing a near real-time processing system, NOAA will generate a series of Environmental Data Records (EDRs) from VIIRS data. For example, the VIIRS Land Surface Temperature (LST) EDR will estimate the surface skin temperature over all global land areas and provide key information for monitoring Earth surface energy and water fluxes. Because both VIIRS and its processing algorithms are new, NOAA is conducting a rigorous calibration and validation program to understand and improve product quality. This paper presents a new validation methodology to estimate the quantitative uncertainty in the LST EDR, and contribute to improving the retrieval algorithm. It employs a physically-based approach to scaling up point LST measurements currently made operationally at many field and weather stations around the world. The scaling method consists of the merging information collected at different spatial resolutions within a land surface model to fully characterize large area $(\mathrm{km} \times \mathrm{km}$ scale) satellite products. The approach can be used to explore scaling issues over terrestrial surfaces spanning a large range of climate regimes and land cover types, including forests and mixed vegetated areas. The methodology was tested successfully with NASA/MODIS data, indicating an absolute error for MODIS LST products of $2.0 \mathrm{~K}$ at a mixed agricultural site (Bondville, IL) when accounting for scaling, and higher than $3 \mathrm{~K}$ without scaling. The VIIRS LST EDR requires a $1.5 \mathrm{~K}$ measurement accuracy and $2.5 \mathrm{~K}$ measurement precision. Ultimately, this validation approach should lead to an accurate and continuously-assessed VIIRS LST product suitable to support weather forecast, hydrological applications, or climate studies. It is readily adaptable to other moderate resolution satellite systems.
\end{abstract}

(c) 2012 Elsevier Inc. All rights reserved.

\section{Introduction}

Energy and water exchanges at the biosphere-atmosphere interface have major influences on the Earth's weather and climate. Numerical models ranging from local to global scales must represent and predict effects of surface fluxes. Land Surface Temperature (LST) is a key variable that helps govern radiative, latent and sensible heat fluxes at the interface. Thus, understanding and monitoring the dynamics of the LST and links with the human induced changes is

\footnotetext{
* Corresponding author at: Cooperative Institute for Climate and Satellites (CICS), North Carolina State University, 151 Patton Avenue, Asheville, NC 28801, USA. Tel.: +1 828257 3007; fax: + 18282573002 .

E-mail address: pierre.guillevic@noaa.gov (P.C. Guillevic).
}

critical for modeling and predicting climate and environmental changes, and for many other applications such as geology, hydrology and vegetation monitoring (Kerr et al., 2004; Moran et al., 2009). For instance, simulations with climate models show that a reduction in vegetation cover modifies the balances of latent and sensible heat fluxes, leading to an increase of LST and a decrease of evapotranspiration and precipitation over land surfaces (Collatz et al., 2000; Guillevic and Koster, 2002; Guillevic et al., 2002; Meng et al., 2009; Shukla and Mintz, 1982). Consequently, LST is an important element of the climate system that can be derived from satellite observations to monitor long-term environmental changes.

The LST Environmental Data Record (EDR) derived from the Visible Infrared Imager Radiometer Suite (VIIRS), a sensor aboard the Suomi National Polar-orbiting Partnership (NPP) and future 
Joint Polar Satellite System (JPSS) platforms, will provide high spatial and temporal resolution images of the LST. This product will provide useful information about surface energy and soil hydrology, and can be used in weather forecast systems or to monitor the climate and climate change (Reichle et al., 2009, 2010). However, LST products are not widely used by operational weather and climate centers through direct analysis or data assimilation in atmospheric models. This point is explained by multiple factors. The LST retrieved from thermal infrared remote sensing measurements needs atmospheric and surface emissivity corrections, which are usually associated with large uncertainties. Moreover, due to the spatial heterogeneity of the land surface, the instrument footprint may encompass a variety of canopy types and soils (Fig. 1), with large variations of emissivity and LST in both space and time. Indeed, LST can vary by 10 Kelvin (K) in just a few meters and up to $50 \mathrm{~K}$ over the daily cycle (Pinheiro et al., 2006a; Prata, 1993, 1994). Thus, satellite measurements often represent a rather complicated weighted mean temperature within a pixel, making LST data retrieval and interpretation difficult. Perhaps for these reasons, very few long-term LST products have been processed (Pinheiro et al., 2006b). Nevertheless, modeling groups are increasingly seeking quality LST times series (Reichle et al., 2010).

Until now, validation of thermal infrared satellite products at moderate resolution was mostly performed over homogeneous surfaces such as lakes (Wan et al., 2002; Wan, 2002, 2008; Hook et al., 2007), deserts (Goettsche et al., in press; Hulley and Hook, 2009a, 2009b; Hulley et al., 2009; Wan, 2002, 2008; Wan et al., 2002) and dense or very homogeneous vegetation covers (Coll et al., 2009; Goettsche et al., accepted for publication; Yu et al., 2010). Two approaches were commonly used: direct comparisons with ground-based LST measurements, and a "radiance-based" method (Coll et al., 2009; Wan and Li, 2008). The latter uses atmospheric temperature and water vapor content profiles with a radiative transfer model to describe the at-sensor atmospheric effect and contribution. This paper concerns the former approach.

In general, most validation studies over relatively homogeneous surfaces find biases between in situ and satellite derived LST of around $1 \mathrm{~K}$ or less (Jacob et al., 2008; Kerr et al., 2004). However, differences can be much larger (e.g., up to $10 \mathrm{~K}$ ) over more heterogeneous landscapes due to unresolved spatial and temporal representativeness (Bosilovich, 2006; Wang and Liang, 2009; Wang et al., 2008) and incorrect retrieval algorithm assumptions and design. Nevertheless, observed biases between ground and satellite-based LST obtained over heterogeneous areas are strongly reduced when using nighttime data (Bosilovich, 2006; Wang et al., 2008) since effects of structural shading, evaporative cooling and surface-air temperature differences are smaller. Thus, heterogeneous surfaces appear more radiatively uniform. Wang et al. (2008) found a $3.1 \mathrm{~K}$ bias between MODIS LST standard products and ground-based LST from a FLUXNET station located in Bondville, IL, USA. Using data from the Surface Radiation Budget (SURFRAD) station, Wang and Liang (2009) found a bias and standard deviation around $-0.1 \mathrm{~K}$ and $1.5 \mathrm{~K}$, respectively, when comparing with nighttime MODIS LST data and around $0.4 \mathrm{~K}$ and $5.6 \mathrm{~K}$, respectively, when comparing with daytime ASTER LST products. Hulley and Hook (2010) showed that using the Temperature Emissivity Separation (TES) algorithm to derive surface emissivity and LST from both ASTER and MODIS data, allow to generate more consistent products and to significantly reduce discrepancies between them. The authors found differences less than $1 \mathrm{~K}$ between aggregated ASTER LST and MODIS LST using the TES algorithm. These results illustrate the fact that due to various scientific methods, LST products generated at different spatial, spectral and temporal resolutions can be significantly different. Such a result is not specific to LST, and several studies have already shown the effect of scaling and aggregation on different parameters or quantities, such as spectral bands and vegetation index (Chen and Henebry, 2009), Leaf Area Index (LAI) and albedo (Liang, 2000) or more globally land surface parameters used in land surface modeling (Intsiful and Kunstmann, 2008). Nevertheless, Hall et al. (2008) and Liu et al. (2006) found very good agreement between MODIS and ASTER LST over Greenland Ice Sheet and part of the Loess Plateau in China, respectively.

The objective of this paper is to present a new validation methodology developed to monitor the quality of the VIIRS LST EDR over both homogeneous and heterogeneous surfaces (e.g., mixed vegetation

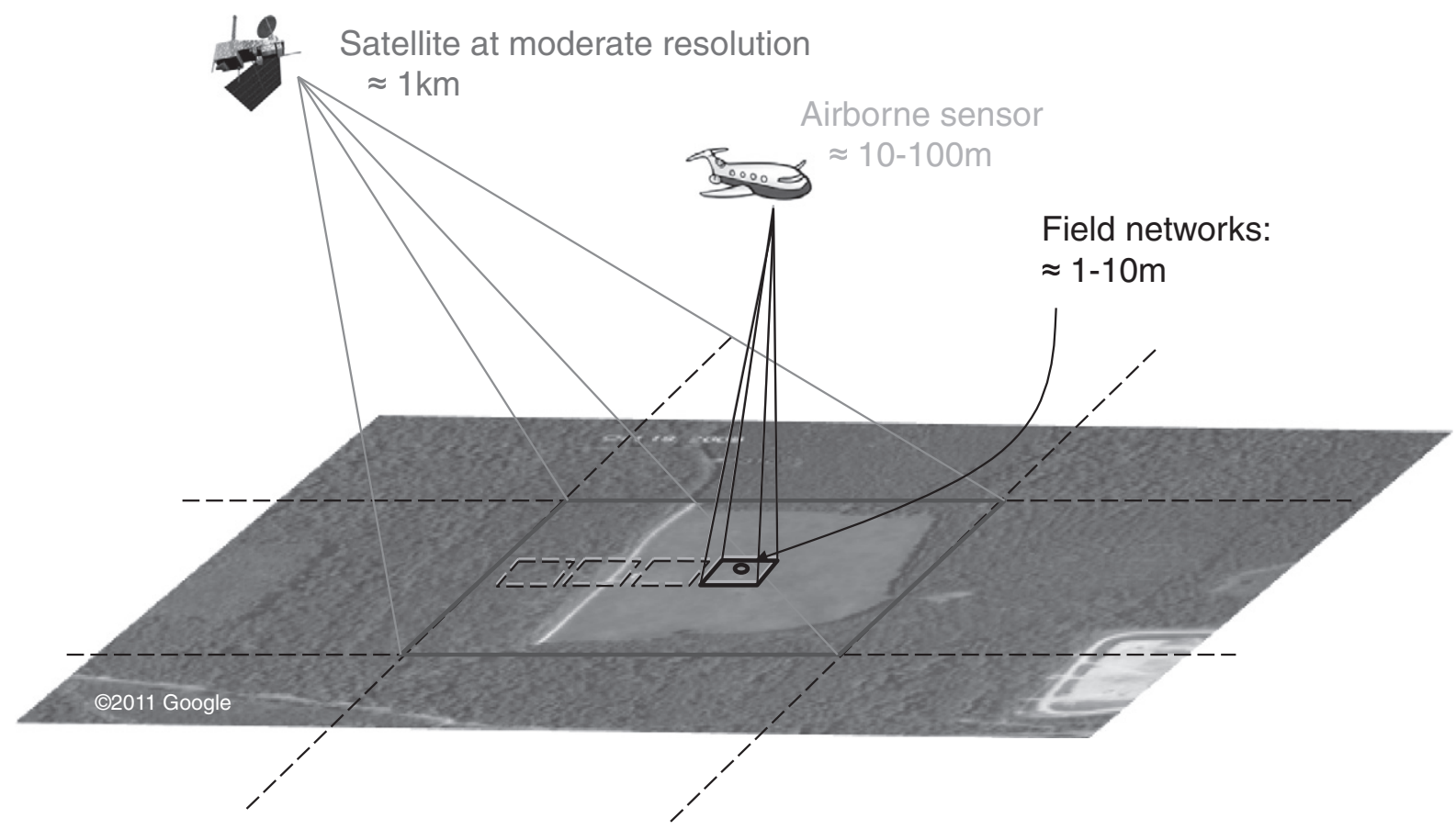

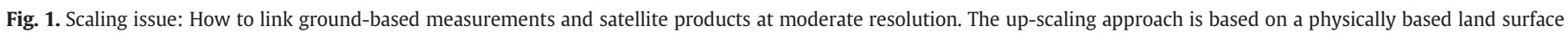
model that uses ground measurements and within pixel information to describe satellite footprints over ground stations. 
classes). The approach combines point field data and fine resolution imagery in a land surface model to characterize the LST over moderate resolution scales (multiple $\mathrm{km}$ ). The model estimates the thermal radiance for each subpixel grid cell, then integrates over all grid cells to provide an LST estimate that is comparable with a VIIRS measurement over the same area (Fig. 1). The model estimation is anchored to near real time field measurements available operationally.

Because VIIRS data were not available during this study, we used MODIS LST products as a proxy and focused on the comparison with field data derived from NOAA's climate observational networks. MODIS and VIIRS LST retrieval algorithms rely on two thermal emissive spectral bands-channels $31(10.78-11.28 \mu \mathrm{m})$ and 32 (11.77$12.27 \mu \mathrm{m})$ for MODIS, and channels $15(10.26-11.26 \mu \mathrm{m})$ and 16 (11.54-12.49 $\mu \mathrm{m})$ for VIIRS-using a split window technique (Becker and Li, 1990; Sobrino and Romaguera, 2004; Wan and Dozier, 1996; Yu et al., 2005, 2009). The spatial resolution of derived LST product at nadir is around $1 \mathrm{~km}$ for MODIS and around $750 \mathrm{~m}$ for VIIRS. The algorithm quality strongly depends on the surface emissivity value used in the split window approach, and errors can be due to a misclassification in observed cover type, or seasonal and dynamic changes in land cover types (Hulley and Hook, 2009a), viewing configurations (Guillevic et al., 2003; Lagouarde et al., 2000; Pinheiro et al., 2006a; Snyder and Wan, 1998; Sobrino et al., 2005; Yu et al., 2009) and atmospheric water vapor content. In order to evaluate the possibility to derive LST using a split window method, Wan and Dozier (1989) have shown that the error in the retrieved LST associated with 0.01 uncertainty in spectral emissivity is usually larger than the error associated with the atmospheric correction using standard atmospheric profiles prescribed in atmospheric radiative transfer models, e.g. LOWTRAN in the numerical study made by the authors.

First, we present the validation methodology, and describe the datasets and the up-scaling algorithm that will be routinely used to evaluate and monitor the quality of VIIRS standard LST products. Then, the approach is tested using MODIS LST collection 5 products (Hulley and Hook, 2009a; Wan, 2008) as proxy for VIIRS products, and ground data from two collocated NOAA's meteorological stations near Bondville, IL, USA, from the US Climate Reference Network and the SURFRAD network. The test site is part of an agricultural landscape, and we assume here that the LST spatial variability within a $1-\mathrm{km}$ satellite pixel is explained by changes in vegetation density.
Indeed, vegetation density influences the surface optical properties (albedo and emissivity), the fraction of Absorbed Photosynthetic Active Radiation (APAR), the transpiration rate, and then affects the surface energy and water budgets, and the LST. In the study, the spatial distribution of vegetation densities is retrieved from MODIS $250 \mathrm{~m}$-NDVI products and then used by the SETHYS land surface model (Coudert et al., 2006) to simulate LST.

\section{Validation methodology description}

The LST validation scheme outlined here is anchored to groundbased observations. For most mixed vegetated landscapes composed of various land cover types or soils, the LST measured by a station at one specific location-i.e., a point measurement-does not represent the surrounding area that is part of the coarser satellite sensor pixel. For example, different land cover types and their associated spatial and temporal variations in surface biophysical parameters, such as vegetation phenology, optical and thermal properties or soil moisture affect the different components of the energy budget. In the present paper, a surface energy model is used to estimate these components for a subpixel cell using commonly-measured surface and meterological parameters. A cell is defined here as an area of homogeneous, or evenly mixed heterogeneous, vegetation cover. The model is executed for each cell or tile, then used to estimate the aggregate LST over all subpixel cells.

The different steps of the scaling methodology and the global LST EDR validation approach (Fig. 2) are:

1. Calibration of the land surface model using ground observations. This task represents the determination of the optimal set of internal model parameters that allows the model to describe the observed in situ LST.

2. Representation of the spatial distribution $\left\{\mathrm{T}_{\mathrm{i}}\right.$ \} of the LST (Eq. 1) within a satellite footprint using the model forced by the observed atmospheric forcing measured by the station and spatial information of biophysical properties of land covers surrounding the station.

$$
T_{i}=T_{\text {station }}^{0}+\Delta T_{i}^{S} \quad \text { with } \quad \Delta T_{i}^{S}=T_{i}^{S}-T_{\text {station }}^{S}
$$

where $T_{i}$ is the LST of tile $i$ around the ground station-assuming that the satellite footprint is represented by $n$ homogeneous tiles with

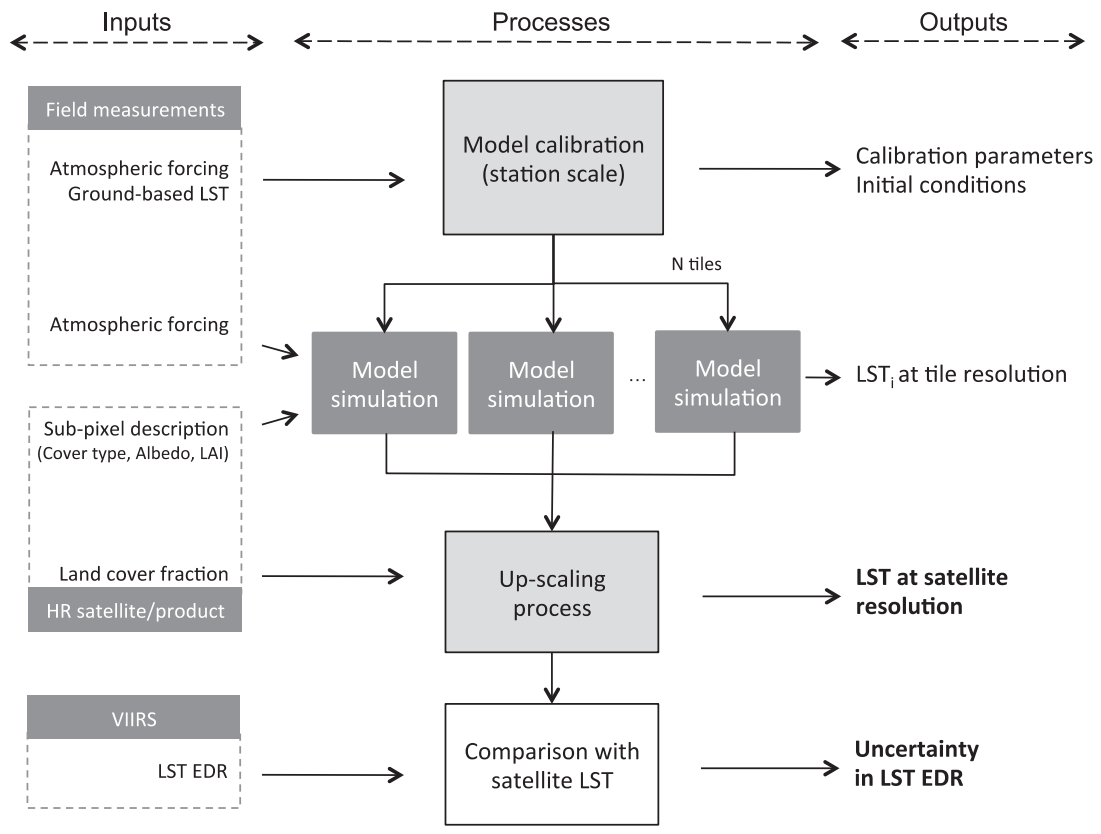

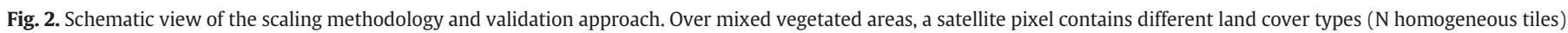
The satellite measurement represents a weighted mean of $\mathrm{N}$ radiative contributions. 
various biophysical properties, $\mathrm{T}^{0}{ }_{\text {station }}$ is the observed LST by the station, $\mathrm{T}_{\mathrm{i}}^{\mathrm{s}}$ and $\mathrm{T}_{\text {station }}^{\mathrm{s}}$ are the LST simulated by the land surface model for tile $\mathrm{i}$ and the tile containing the station. $\mathrm{T}^{\mathrm{s}}{ }_{\text {station }}$ represents the result of the previous step.

3. Aggregation of the emissive fluxes associated with the spatial distribution $\left\{\mathrm{T}_{\mathrm{i}}\right\}$ of the LST around the station and calculation of $\mathrm{T}_{\text {pixel }}$, the LST value at satellite resolution (Eq. 2) that represents a weighted mean of the $n$ cells or tiles. Here, the aggregation does not account for the system's point spread function and the fact that, in practice, the observations have elliptical shapes.

$T_{\text {pixel }}=\left(\frac{1}{\varepsilon_{\text {pixel }} \sigma} \sum_{i=1}^{n} \varepsilon_{i} \sigma T_{i}^{4} c_{i}\right)^{\frac{1}{4}}$ with $\quad \varepsilon_{\text {pixel }}=\sum_{i=1}^{n} \varepsilon_{i} c_{i}$

where $\mathrm{T}_{\text {pixel }}$ is the LST at satellite resolution, $\sigma$ is the StephanBoltzmann constant $\left(\approx 5.67 \times 10^{-8} \mathrm{~W} \mathrm{~m}^{-2} \mathrm{~K}^{-4}\right)$, and $\varepsilon_{\mathrm{i}}, \mathrm{T}_{\mathrm{i}}$ and $\mathrm{c}_{\mathrm{i}}$ are the broadband emissivity, the LST and the cover fraction of tile i. The cover fraction $c_{i}$ is an input of the methodology and depends on the ancillary data available to describe the within satellite pixel variability. The surface emissivity $\varepsilon_{\mathrm{i}}$ of each tile composing the satellite pixel is calculated by the model accounting for the vegetation density and the soil emissivity. These values could be derived from remote sensing data at high resolution, such as ASTER data (Hulley and Hook, 2009b).

The land surface model is used to quantify differences in subpixel temperature between classes of surface biophysical properties (Eq. 1), i.e. different surface types or different vegetation densities. This allows to reduce the influence of model systematic errors and uncertainties in the atmospheric forcing on the assessment of the satellite pixel LST
$\left(\mathrm{T}_{\text {pixel }}\right)$. The various methods, models, and requested data used in our study are described in the following sections.

\section{The SETHYS land surface model}

\subsection{Model description}

The SETHYS-for "Suivi de l'ETat HYdrique des Sols", French acronym for Soil Moisture Monitoring-land surface model (Coudert et al., 2006) is a one dimensional soil-vegetation-atmosphere transfer model that especially represents the LST diurnal cycle and the associated response of remote sensing sensors, accounting for specific spectral domains and viewing configurations. The model has been used in various agricultural and hydrological applications (Coudert and Ottlé, 2007; Coudert et al., 2008; Saux-Picart et al., 2009a, 2009b). The model needs atmospheric forcing and surface biophysical parameters as inputs, simulates the energy and water exchanges between the surface and the atmosphere, and describes the evolution of surface state variables, e.g. soil and canopy temperatures, air temperature and specific humidity within the canopy, and soil water content. The land surface system is represented by two components, the soil and the vegetation canopy, and each component is characterized by a set of biophysical parameters and acts as a source of energy. The canopy is considered as a semi-transparent and turbid medium, and the vegetation density is then a determining factor in partitioning the incoming radiation. The heat and water transfers calculation within the continuum soil-vegetation-atmosphere is based on a resistance concept, considering the vegetation canopy as a single source of energy located at a reference height, $z_{a e r o}$, above the ground (Fig. 3). The convective latent and sensible heat fluxes are determined by integration of the

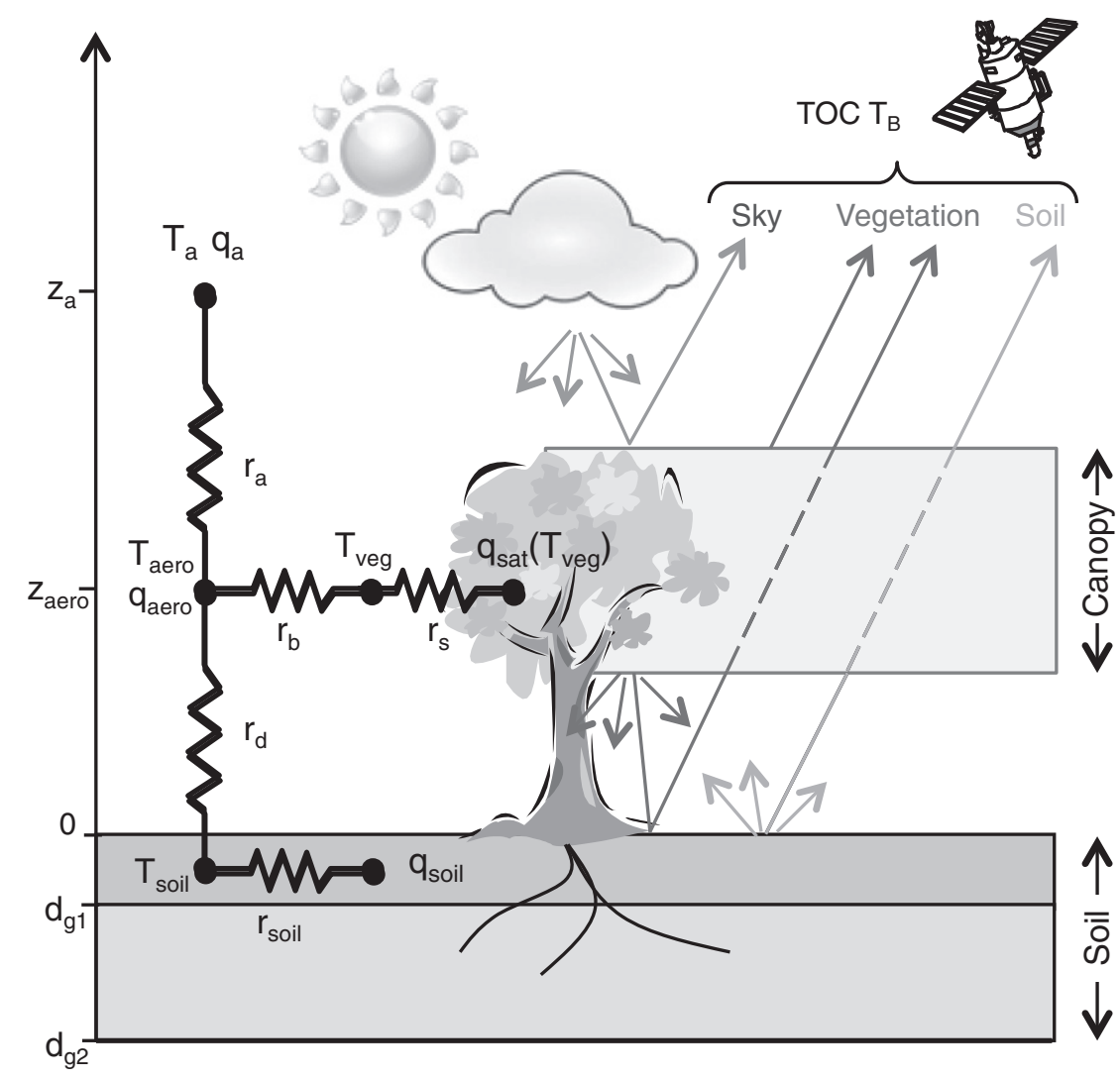

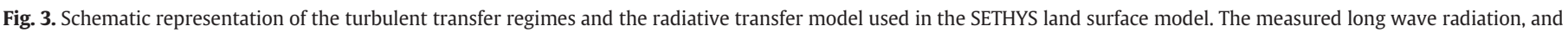

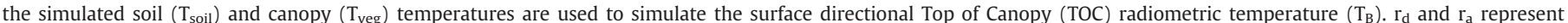

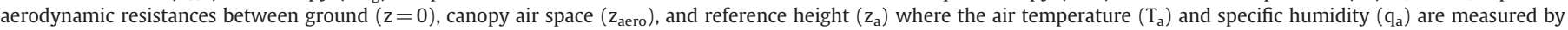

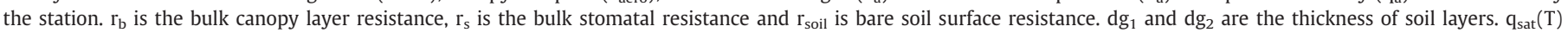
represents the saturated humidity at temperature $\mathrm{T}$. $\mathrm{T}_{\text {aero, }}, \mathrm{q}_{\mathrm{aero}}, \mathrm{T}_{\text {soil }}$, and $\mathrm{q}_{\text {soil }}$ represent the temperature and humidity of the canopy air and soil surface. 
equation for momentum, mass and heat exchanges between the surface, the canopy and a reference level, $\mathrm{z}_{\mathrm{a}}$, above the canopy where the air temperature and specific humidity are measured (Deardorff, 1978; Thom, 1972). The SETHYS model has a two-layer soil hydrology conceptual model (Deardorff, 1978): the upper layer (5 to $20 \mathrm{~cm}$ thick) affects the exchange with the atmosphere and is included in a second layer that represents the total root zone whose thickness depends on the overlaying vegetation type. The model physics and the main parameterizations are described and discussed by Coudert et al. (2006).

The SETHYS land surface model had been chosen for this study because of its ability (i) to represent all physical processes that affect and characterize the LST, and (ii) to simulate remote sensing data. Indeed, the model is coupled with a radiative transfer model in both shortwave and infrared domains (François, 2002) to account for satellite viewing configurations, and thus simulates directional brightness temperatures. The model accounts for the root zone water stress and its effect on LST through computation of the stomatal conductance (Collatz et al., 1992; Guillevic et al., 2002; Sellers et al., 1992, 1996a). The vegetation classification used by the SETHYS model (Table 1) and associated photosynthesis and stomatal conductance parameterizations are the same as those of the commonly-used SiB model (Sellers et al., 1996b).

\subsection{Model calibration}

The parameterizations of energy and water transfers used in the SETHYS model are conceptual and involve a set of parameters that cannot be routinely measured at ground level. For a given application, several model parameters and initial conditions need to be estimated in order to obtain reliable simulated surface fluxes and LST. A list of model parameters and their range of plausible values is presented in Table 2. Field-measured values can of course be used as available.

Although this is a relatively large list, it can be reduced a priori by calibrating the model to a given field site such that not all parameters must be independently measured in situ. Model calibration consists of the minimization of a cost function expressing the divergence between model outputs and observations. In order to achieve a robust model calibration, the multi-objective calibration iterative process (MCIP; Demarty et al., 2004, 2005) was applied. Based on a stochastic Monte Carlo approach, the MCIP methodology represents the reduction of an initial parameter space (initial parameter ranges are defined in Table 2) by the optimization of one or several model outputs against observations, e.g., LST, surface fluxes, etc. The methodology consists of three main steps: (1st) the generation of an ensemble of simulations6000 in this case for each iteration, as defined by Coudert et al. (2006) or Saux-Picart et al. (2009a)-by sampling an initial parameter space, (2nd) the iterative Pareto ranking (Bastidas et al., 1999; Gupta et al., 1999), or a simple sorting if there is only one objective, of the best

Table 1

Vegetation classification schemes used in the SETHYS model-from Sellers et al. (1996b). The perennial grasses are classified as either C3 or C4 plants. These terms refer to the different pathways that plants use to capture carbon dioxide during photosynthesis: 3 carbon for C3 and 4 carbon for C4.

\begin{tabular}{ll}
\hline Type & Name \\
\hline 1 & Broadleaf-evergreen trees \\
2 & Broadleaf-deciduous trees \\
3 & Broadleaf and needleleaf trees \\
4 & Needleleaf-evergreen trees \\
5 & Needleleaf-deciduous trees \\
6 & Short vegetation/C4 grassland \\
7 & Broadleaf shrubs with bare soil \\
8 & Dwarf trees and shrubs \\
9 & Agriculture/C3 grassland \\
\hline
\end{tabular}

Table 2

List of model parameters and initial variables with their uncertainty ranges.

\begin{tabular}{|c|c|c|c|}
\hline Name & Description & $\begin{array}{l}\text { Parameter } \\
\text { range }\end{array}$ & Unit \\
\hline \multicolumn{4}{|c|}{ Optical properties } \\
\hline$\varepsilon_{\mathrm{g}}$ & Bare soil emissivity & $0.92-0.96$ & - \\
\hline$\alpha_{\text {dry }}$ & Dry soil albedo & $0.2-0.4$ & - \\
\hline$\alpha_{\text {wet }}$ & Wet soil albedo & $0.1-0.2$ & - \\
\hline $\mathrm{w}_{\mathrm{dry}}$ & $\begin{array}{l}\text { Soil moisture threshold for albedo } \\
\text { calculation }\end{array}$ & $0.15-0.3$ & $\mathrm{~m}^{3} \mathrm{~m}^{-3}$ \\
\hline $\mathrm{w}_{\text {wet }}$ & $\begin{array}{l}\text { Soil moisture threshold for albedo } \\
\text { calculation }\end{array}$ & $0.3-0.5$ & $\mathrm{~m}^{3} \mathrm{~m}^{-3}$ \\
\hline$\alpha_{\text {veg }}$ & Vegetation albedo & $0.15-0.35$ & - \\
\hline \multicolumn{4}{|c|}{ Vegetation properties } \\
\hline $\mathrm{V}_{\max 0}$ & Leaf photosynthesis capacity & $30-200$ & $\mu \mathrm{mol} \mathrm{m}{ }^{-2} \mathrm{~s}^{-1}$ \\
\hline$l_{\text {leaf }}$ & $\begin{array}{l}\text { Leaf dimension along the wind } \\
\text { direction }\end{array}$ & $0.02-0.1$ & $\mathrm{~m}$ \\
\hline $\mathrm{k}_{\mathrm{wstr}}$ & Parameter for water stress calculation & $0.01-0.1$ & - \\
\hline \multicolumn{4}{|c|}{ Soil properties } \\
\hline $\mathrm{p}_{\mathrm{hc}}$ & Half critic hydrologic potential & -200 to -100 & $\mathrm{~m}$ \\
\hline $\mathrm{w}_{\max }$ & Saturated soil water content & $0.3-0.5$ & $\mathrm{~m}^{3} \mathrm{~m}^{-3}$ \\
\hline $\mathrm{W}_{\text {resid }}$ & Residual soil water content & $0.05-0.15$ & $\mathrm{~m}^{3} \mathrm{~m}^{-3}$ \\
\hline$h_{V G}$ & Scale factor in Van Genuchten model & $-1.2-0.3$ & - \\
\hline$n_{V G}$ & $\begin{array}{l}\text { Shape parameter in Van Genuchten } \\
\text { model }\end{array}$ & $1.1-1.4$ & - \\
\hline $\mathrm{K}_{\text {sat }}$ & Saturated hydraulic conductivity & $\begin{array}{l}2.4 \times 10^{-8} \\
2.7 \times 10^{-6}\end{array}$ & $\mathrm{~m} \mathrm{~s}^{-1}$ \\
\hline $\mathrm{a}_{\text {Elim }}$ & Parameter for potential soil evaporation & $1-50$ & - \\
\hline$b_{\text {Elim }}$ & Parameter for potential soil evaporation & $1-50$ & - \\
\hline $\mathrm{f}_{\text {therm }}$ & $\begin{array}{l}\text { Correction coefficient of the soil } \\
\text { volumetric heat capacity }\end{array}$ & $1-6$ & - \\
\hline$d_{\mathrm{g} 1}$ & Soil surface layer depth & $0.05-0.25$ & $\mathrm{~m}$ \\
\hline$d_{\mathrm{g} 2}$ & Root zone depth & $0.5-2.0$ & $\mathrm{~m}$ \\
\hline \multicolumn{4}{|c|}{ Initial conditions } \\
\hline$\Delta \mathrm{w}_{\mathrm{g} 1,0}$ & $\begin{array}{l}\text { Uncertainty in initial soil surface layer } \\
\text { water content }\end{array}$ & $-0.02-0.02$ & $\mathrm{~m}^{3} \mathrm{~m}^{-3}$ \\
\hline$\Delta \mathrm{w}_{\mathrm{g} 2,0}$ & $\begin{array}{l}\text { Uncertainty in initial root zone water } \\
\text { content }\end{array}$ & $-0.02-0.02$ & $\mathrm{~m}^{3} \mathrm{~m}^{-3}$ \\
\hline$\Delta \mathrm{T}_{\mathrm{g} 2,0}$ & $\begin{array}{l}\text { Uncertainty in initial deep soil } \\
\text { temperature }\end{array}$ & $-2.0-2.0$ & $\mathrm{~K}$ \\
\hline
\end{tabular}

simulations (in term of matching the observations), and (3rd) the determination of the a posteriori ranges of sensitive parameters, which are used to generate a new ensemble of simulations at the next iteration. The calibration is generally achieved after a few iterations when cost functions have reached a global minimum. Coudert et al. (2006) showed that the calibration of the SETHYS land surface model is performed with good accuracy and robustness after a maximum of ten iterations when surface fluxes are used as optimization variables. In this study, the same methodology has been successfully adapted to adjust the SETHYS model using observed LST dataset, as the LST describes the energy budget (Eq. 1). Here, the procedure simultaneously minimizes two cost functions defined as the bias and the root mean square error (RMSE) between simulated and observed LST. It is important to note that parameters, which are relatively not sensitive at one iteration, are let free to vary in their a priori uncertainty range at the next iteration. All parameters or initial conditions do not influence the model outputs in the same way and thus do not need to be estimated with the same accuracy. It is therefore important to identify the most sensible parameters in order to improve the efficiency of the calibration technique and to quantify the model uncertainties.

The SETHYS model has been validated against field data for various agricultural landscapes located Southeastern France (Coudert et al., 2006) and North of France (Ottlé et al., 2008). These studies have shown that the uncertainty in simulated LST associated with model parameterization is around $1 \mathrm{~K}$ when the atmospheric forcing and vegetation density are well characterized. In the present study, we have found similar differences between simulated and measured LST after the calibration process. 


\section{Test site and data description}

\subsection{Test site description}

In order to test our validation methodology, we have selected a site located in a mixed agricultural area near Bondville, IL, USA. The latitude and longitude coordinates of the site location are $40.05^{\circ} \mathrm{N}$ and $88.37^{\circ} \mathrm{W}$, respectively. The site is a 14 -acre (around $0.06 \mathrm{~km}^{2}$ ) area covered with a mix of prairie grass and clover (Fig. 4). The surface has not changed since 1995 and is mowed once per year, usually in October. Typically, the grass is around $1 \mathrm{~m}$ high during the year. The site is surrounded by corn and soybean crops with a different phenology than the grassland. We have selected this site because two NOAA's stations from the US Climate Reference Network (USCRN) (Leduc et al., 2009; Menne et al., 2010) and the Surface Radiation Budget (SURFRAD) network (Augustine et al., 2000, 2005) are collocated on the same parcel. Complementary data were available to develop and test the validation methodology. Actually, USCRN stations do not measure the incoming longwave radiation, SURFRAD stations do not measure precipitation, and both quantities are input parameters requested by the SETHYS model. In this study, we used wind speed, shortwave and longwave radiation measurements from the SURFRAD station that is specifically designed for radiation measurements, and the other meteorological variables (air temperature and humidity, precipitation, soil temperature and moisture profiles) from the USCRN station.

\subsection{The US Climate Reference Network (USCRN)}

The USCRN provides weather and climate measurements over 114 stations developed, deployed, managed, and maintained by the National Oceanic and Atmospheric Administration (NOAA) in the continental United States for the express purpose of detecting the signal of climate change (Leduc et al., 2009; Menne et al., 2010). The USCRN provides stable surface air temperature and relative humidity, precipitation, soil temperature and moisture, solar radiation and surface radiometric temperature observations that are accurate and representative of local environmental conditions (Fig. 5). Station site location has been carefully defined to avoid areas subject to manmade influences (e.g., land cover change). Accurate climate representativeness and long-term maintenance at each USCRN station location are essential requirements for a long-term validation process for VIIRS LST.

As 5-minute and hourly observations are collected at each USCRN station, three one-hour records of observations are transmitted via GOES satellite telemetry to NCDC once per hour. The observations are quickly processed at NOAA's National Climatic Data Center (NCDC) to ensure data quality and for computation of official 5-minute and hourly observations from the multi-sensor configuration. This latest point makes it possible for near real time product quality assessment for the users community.

The Apogee Instruments IRTS-P infrared temperature sensor measures the Thermal Infrared (TIR) radiometric ground surface temperature in a wavelength band from 6 to $14 \mu \mathrm{m}$. The accuracy of the sensor is $0.2{ }^{\circ} \mathrm{C}$ from $15^{\circ}$ to $35^{\circ} \mathrm{C}$ and $0.3^{\circ} \mathrm{C}$ from $5^{\circ}$ to $45^{\circ} \mathrm{C}$, and the precision is $0.05^{\circ}$ from $15^{\circ}$ to $35^{\circ} \mathrm{C}$ (from factory calibration; http://www.campbellsci.com/irts-p-specifications). The sensor is sampled every $2 \mathrm{~s}$ and these two-second samples are averaged to obtain 5-minute values. The sensor has a 3:1 field of view (FOV), i.e., at $3 \mathrm{~m}$ ( $1.3 \mathrm{~m}$, respectively) from sensor, the FOV is a $1 \mathrm{~m}(0.4 \mathrm{~m}$, respectively) diameter circle. It is mounted vertically downward near the end of a 3-meter cross-member arm, $1.3 \mathrm{~m}$ above the ground surface.

\subsection{The Surface Radiation Budget Network (SURFRAD)}

The Surface Radiation Budget Network (SURFRAD) was established in 1993 with its primary objective to support climate research with accurate, continuous, long-term measurements of the surface radiation budget over the United States.

Currently seven SURFRAD stations are operating in climatologically diverse regions. Independent measures of upwelling and downwelling, solar and infrared are the primary measurements; ancillary observations include direct and diffuse solar, photosynthetically active radiation, UVB, spectral solar, and meteorological parameters (Fig. 4). SURFRAD includes ancillary data (e.g., cloud cover, moisture)

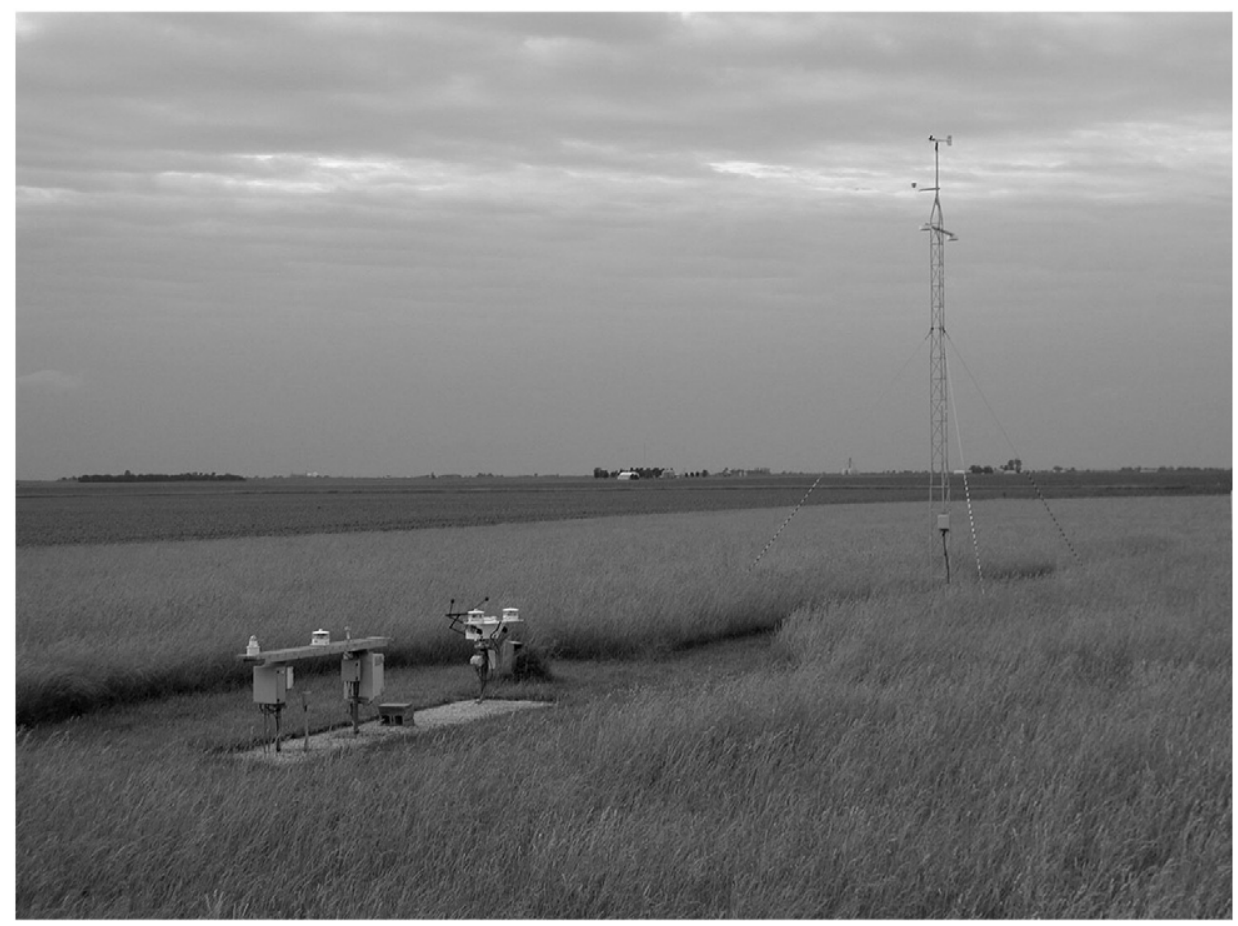

Fig. 4. Picture of the SURFRAD station located in Bondville, IL. The site is a 14-acre area covered with a mix of prairie grass and clover. 


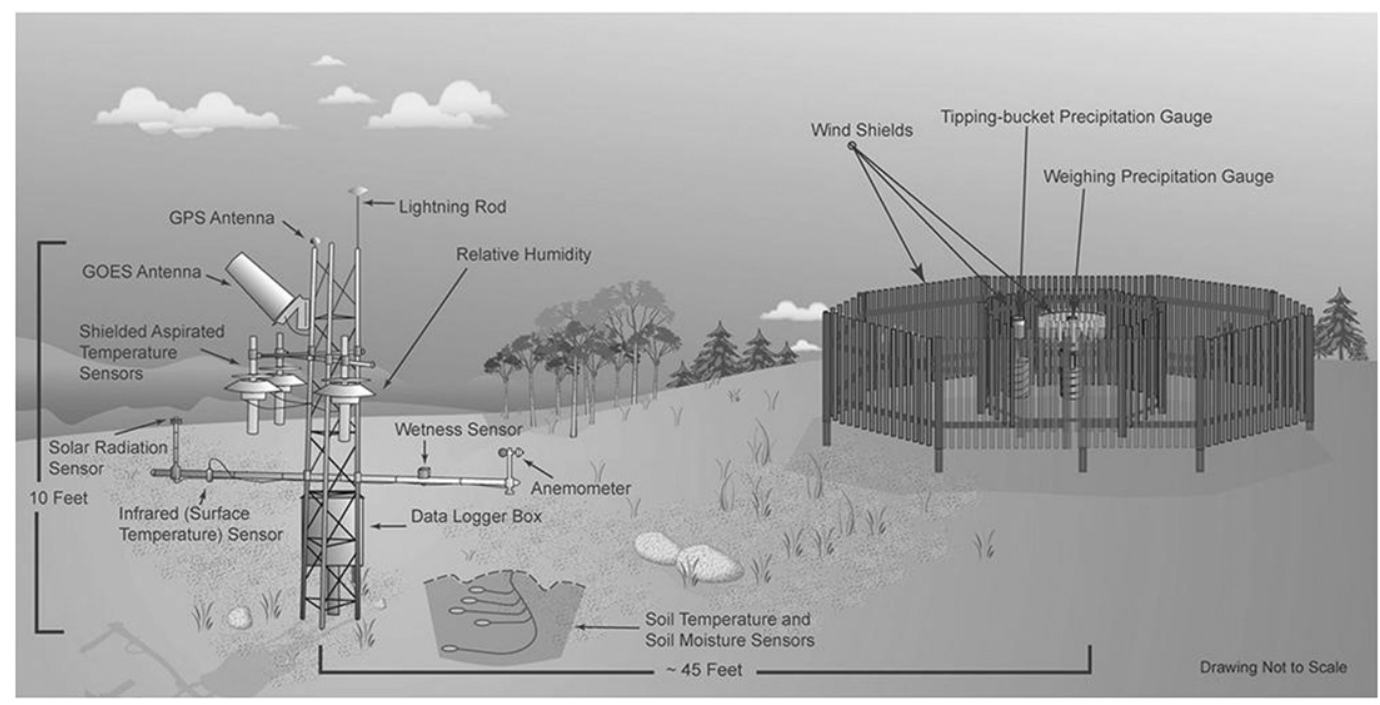

Fig. 5. Schematic description of a US Climate reference Network station. Each station has the same design.

that affect the transfer of solar and thermal infrared radiation to and from the surface. Data are downloaded, quality controlled, and processed into daily files that are distributed in near real time. Observations from SURFRAD have been used for evaluating satellite-based estimates of surface radiation (Su et al., 2007), albedo (Jin et al.,

Table 3

Periods of time selected to evaluate the validation scheme. Quality flags associated with MODIS scenes are used to define periods with no obvious and persistent clouds over the area. The number of quality-controlled MODIS scenes available for each period is indicated.

\begin{tabular}{lllllr}
\hline Period \# & First day (DoY) & Last day (DoY) & \multicolumn{3}{l}{$\begin{array}{l}\text { Number of “clear sky" } \\
\text { MODIS data }\end{array}$} \\
\cline { 3 - 6 } & & & Daytime & Nighttime & Total \\
\hline 1 & April 8 (98) & April 18 (108) & 8 & 12 & 20 \\
2 & June 14 (165) & June 28 (179) & 6 & 3 & 9 \\
3 & August 6 (218) & August 16 (228) & 8 & 4 & 12 \\
4 & August 27 (239) & September 6 (249) & 10 & 7 & 17 \\
5 & September 29 (272) & October 9 (282) & 15 & 17 & 32 \\
6 & October 12 (285) & October 22 (295) & 8 & 14 & 22 \\
Total & & & 55 & 58 & 113 \\
\hline
\end{tabular}

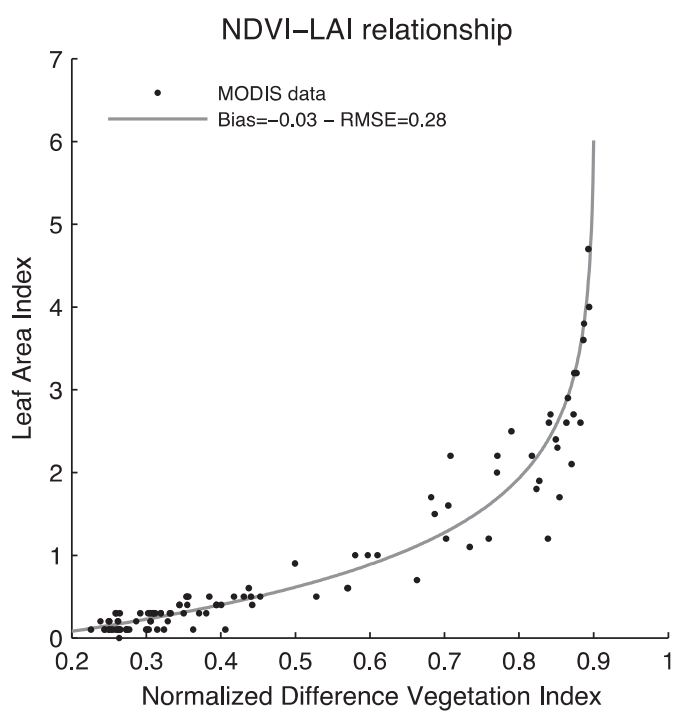

2003) or LST (Wang and Liang, 2009), and for validating hydrologic, weather prediction, and climate models (Augustine et al., 2005). The SURFRAD instruments are meticulously maintained, and all instruments are replaced on an annual basis with freshly calibrated instruments.

The primary measurements used in this study are the upwelling and downwelling thermal infrared irradiances that are measured by two pyrgeometers (Eppley Precision Infrared Radiometer) in the spectral range from 3.5 to $50.0 \mu \mathrm{m}$. The accuracy of the Eppley pyrgeometer is about $4.2 \mathrm{~W} \mathrm{~m}^{-2}$, and the precision of the instrument is less than $1 \mathrm{~W} \mathrm{~m}^{-2}$ for nighttime measurements and around $2 \mathrm{~W} \mathrm{~m}^{-2}$ for daytime measurements (Philipona et al., 1998, 2001). These measurements allow to derive LST values (Eq. 3 ) at a spatial representativeness around $100 \times 100 \mathrm{~m}^{2}$. According to the instrumental error, the uncertainty of the retrieved LST is less than $1 \mathrm{~K}$.

$\mathrm{LW}_{\text {out }}=(1-\varepsilon) \mathrm{LW}_{\text {in }}+\varepsilon \sigma T_{s}^{4}$

where $\mathrm{LW}_{\text {out }}$ and $\mathrm{LW}_{\text {in }}$ are the upwelling and downwelling longwave radiations measured by the SURFRAD station, $\varepsilon$ is the broadband surface emissivity and $\mathrm{T}_{\mathrm{S}}$ is the surface temperature.

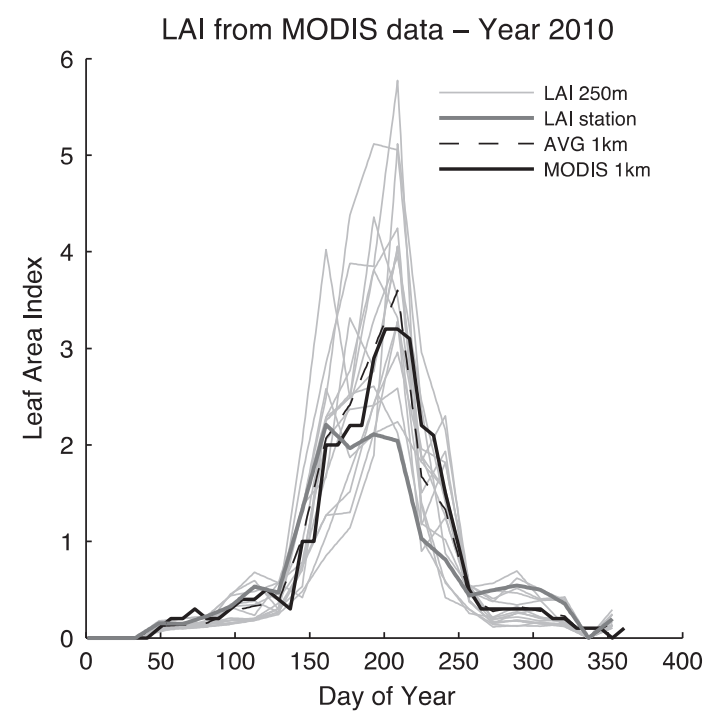

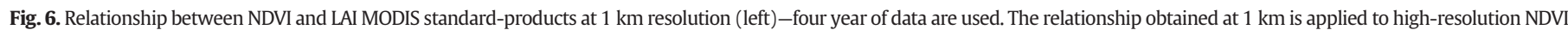
data to derive LAI values at $250 \mathrm{~m}$ resolution (right). The averaged LAI value of the 16 sub-pixels included in a $1 \mathrm{~km}$ pixel and the MODIS LAI standard-product at $1 \mathrm{~km}$ are represented. 

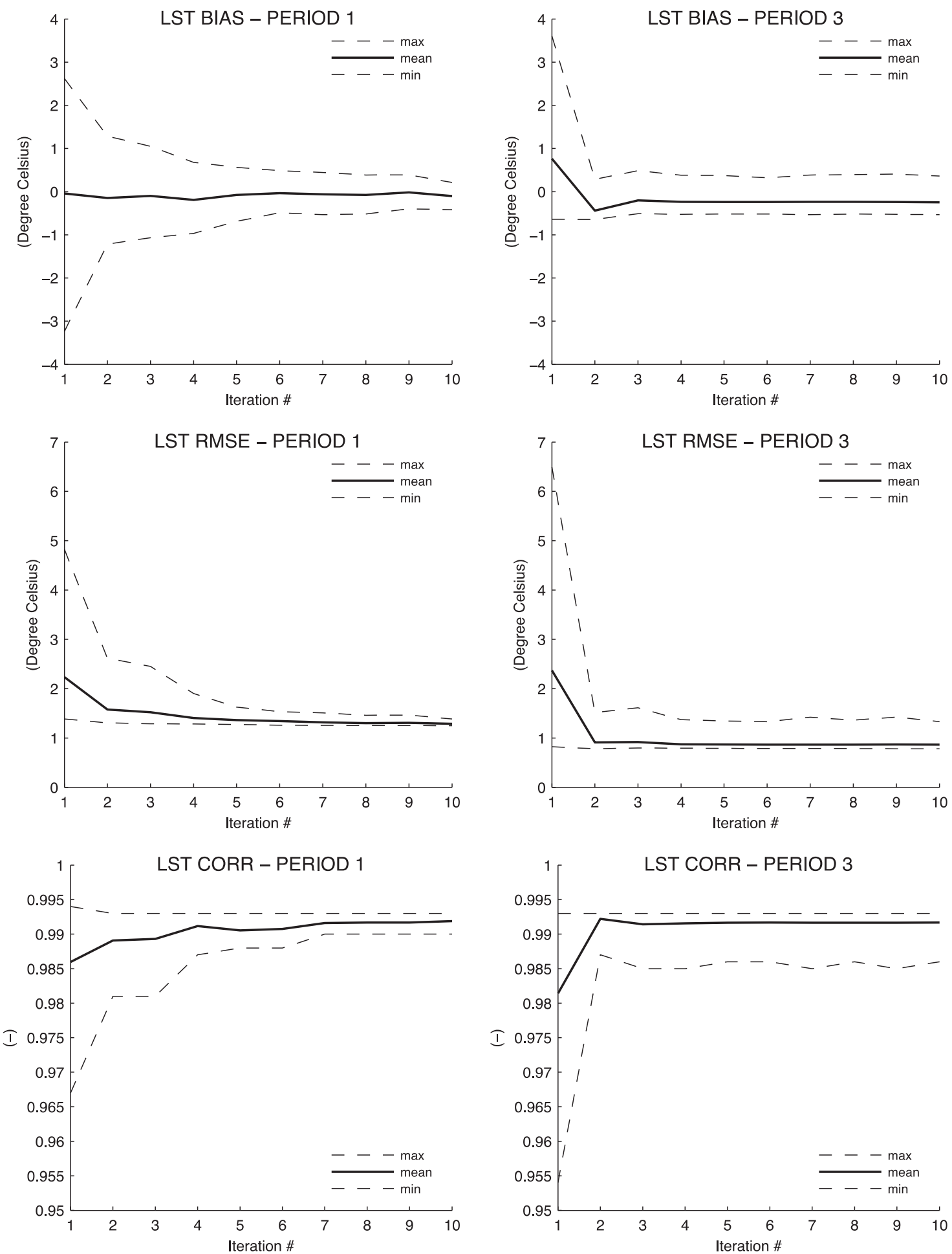

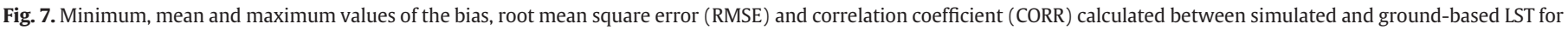
each iteration of the MCIP algorithm. Each iteration represents an ensemble of 6000 simulations. Results are for validation periods 1 (left) and 3 (right).

\subsection{MODIS instruments and products}

We use land surface products derived from the Moderate Resolution Imaging Spectroradiometers (MODIS) onboard Terra and Aqua satellites to develop and evaluate the VIIRS validation methodology.

The MODIS instrument acquires data in 36 spectral channels (Barnes et al., 1998). It scans $\pm 55^{\circ}$ from nadir and provides daytime and nighttime imaging of any point on the Earth every day. Channels
31 and 32 centered on 11.03 and $12.02 \mu \mathrm{m}$, respectively, are used to produce LST products that are used in this study. MODIS IR radiances have a ground resolution of around $1 \mathrm{~km}$ at nadir. MODIS IR radiances are calibrated with a cold space view and full aperture black body viewed before and after each Earth view.

We use the LST Collection 5 product suite (MOD11 for Terra and MYD11 for Aqua products) developed by Wan et al. (2002) and refined by Wan (2008). Based on the local split-window technique 
developed by Becker and Li (1990), Wan and Dozier (1996) developed a view angle dependent generalized split-window algorithm to correct for absorption and re-emission of radiation by atmospheric gases, predominately water vapor, and derive the LST product from MODIS bands 31 and 32. The emissivity of the surface is sensitive to the sensor viewing angle (Dozier and Warren, 1982; Salisbury and D'Aria, 1992; Salisbury et al., 1994) and this effect is not accounted for in the algorithm due to the lack of information about surface emissivity at satellite resolution. The algorithm uses prescribed spectral emissivity values that are derived from land classification maps, and produces a swath product (MOD11_L2 or MYD_L2). For bands 31 and 32, the emissivities used in the algorithm to compute LST over the observational station in Bondville, IL (cropland) are around 0.982 for band 31 and 0.986 for band 32, and do not vary seasonally (Wan et al., 2002). The gridded LST product (MOD11A1 or MYD11A1) is developed from the swath product and is provided on a sinusoidal grid at $\approx 927 \mathrm{~m}$ resolution. The daily daytime and nighttime gridded LST products derived from both MODIS Terra and MODIS Aqua were used in this study. The accuracy of these products is reported to be $1 \mathrm{~K}$ for the surfaces with known emissivity (Wan et al., 2002).

To describe the spatial variability of surface biophysical parameters around the ground stations, we use additional MODIS products (Justice et al., 1998) derived from MODIS Terra instrument only (referred as MOD) or both MODIS Terra and Aqua instruments (referred as MCD): the vegetation index at $250 \mathrm{~m}$ (MOD13Q1) and $1 \mathrm{~km}$ (MOD13A2) spatial resolution and the vegetation density, i.e., leaf area index, at $1 \mathrm{~km}$ spatial resolution (MCD15A2). A full description of every product is available on-line at the NASA Land Processes Distributed Active Archive Center (LPDAAC) website (https://lpdaac. usgs.gov/lpdaac/products/modis_products_table/).

The scaling methodology requires high resolution information about vegetation density, and MODIS Leaf Area Index (LAI) standard product is provided at only $1 \mathrm{~km}$ resolution (Myneni et al., 2002). We use a relationship between the Normalized Difference Vegetation Index (NDVI) and the LAI of vegetation covers (Asrar et al., 1984) to estimate the LAI at $250 \mathrm{~m}$ resolution (Eq. (4)). The relationship has been widely used for agricutural or hydrological applications (Bsaibes et al., 2009; Courault et al., 2008, 2010; Wilson and Meyers, 2007). The relation is calibrated here using NDVI and LAI values derived from MODIS data at $1 \mathrm{~km}$. Then, we use the relationship to estimate LAI at $250 \mathrm{~m}$ resolution using MODIS NDVI product at $250 \mathrm{~m}$ resolution as input. In our case and during the crop season, the 1-km MODIS pixel represents a mix of short vegetation canopies at various growing stage: grassland, corn and soybean crops. We assume that the derived relation does not depend on the vegetation species and can be applied to pixels at higher resolution that may represent a specific vegetation cover.

$\mathrm{LAI}=-\frac{1}{K_{L A I}} \ln \left(\frac{\mathrm{NDVI}-\mathrm{NDVI}_{\infty}}{\mathrm{NDVI}_{S}-\mathrm{NDVI}_{\infty}}\right)$

where $\mathrm{NDVI}_{\infty}$ is the asymptotic value of NDVI when LAI tends towards a maximum value, that was practically around 6.0 in this study, $\mathrm{NDVI}_{s}$ is the bare soil NDVI value and $\mathrm{K}_{\mathrm{LAI}}$ is the extinction coefficient that depends on the cover type. The three parameters are adjusted using the simplex method to minimize the Root Mean Square Error (RMSE) between measured and calculated LAI using data at $1 \mathrm{~km}$ resolution. Because MODIS (or VIIRS-derived) LAI data can be used, rather than field LAI measurements, the validation approach can be used at remote locations lacking LAI measurement equipment and personnel.

\section{Results}

To evaluate the performance of the LST product validation methodology, we have compared LST scaled-up data with daytime and nighttime MODIS LST standard-data products. All data are publicly available data and provided with quality assurance.

\subsection{Experimental design}

The experiment is based on one year of data collected by MODIS and two NOAA's ground stations (USCRN and SURFRAD) in 2010. We have searched for satellite overpasses with no obvious clouds and we have used the quality flag associated with MODIS LST standard-products to select six periods of time with significant clear

Table 4

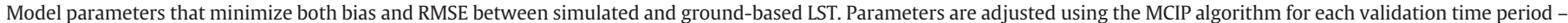
initial ranges are defined in Table 2 . See Table 2 for parameter description.

\begin{tabular}{|c|c|c|c|c|c|c|c|}
\hline \multirow[t]{2}{*}{ Name } & \multicolumn{6}{|c|}{ Validation period } & \multirow[t]{2}{*}{ Unit } \\
\hline & 1 & 2 & 3 & 4 & 5 & 6 & \\
\hline$\varepsilon_{\mathrm{g}}$ & 0.92 & 0.92 & 0.93 & 0.92 & 0.93 & 0.92 & - \\
\hline$\alpha_{\text {dry }}$ & 0.35 & 0.32 & 0.31 & 0.25 & 0.32 & 0.35 & - \\
\hline$\alpha_{\text {wet }}$ & 0.22 & 0.17 & 0.15 & 0.22 & 0.19 & 0.18 & - \\
\hline $\mathrm{w}_{\mathrm{dry}}$ & 0.30 & 0.25 & 0.21 & 0.30 & 0.29 & 0.29 & $m^{3} m^{-3}$ \\
\hline $\mathrm{w}_{\text {wet }}$ & 0.49 & 0.31 & 0.34 & 0.37 & 0.40 & 0.41 & $\mathrm{~m}^{3} \mathrm{~m}^{-3}$ \\
\hline$\alpha_{\text {veg }}$ & 0.23 & 0.25 & 0.26 & 0.22 & 0.31 & 0.30 & - \\
\hline $\mathrm{V}_{\max 0}$ & 197 & 96 & 106 & 182 & 160 & 184 & $\mu \mathrm{mol} \mathrm{m}{ }^{-2} \mathrm{~s}^{-1}$ \\
\hline $\mathrm{l}_{\text {leaf }}$ & 0.06 & 0.04 & 0.04 & 0.04 & 0.06 & 0.05 & $\mathrm{~m}$ \\
\hline $\mathrm{k}_{\mathrm{wstr}}$ & 0.05 & 0.10 & 0.08 & 0.01 & 0.09 & 0.08 & - \\
\hline $\mathrm{p}_{\mathrm{hc}}$ & -135 & -109 & -175 & -185 & -124 & -176 & $\mathrm{~m}$ \\
\hline $\mathrm{w}_{\max }$ & 0.49 & 0.47 & 0.40 & 0.41 & 0.40 & 0.46 & $\mathrm{~m}^{3} \mathrm{~m}^{-3}$ \\
\hline $\mathrm{W}_{\text {resid }}$ & 0.13 & 0.13 & 0.09 & 0.15 & 0.08 & 0.06 & $\mathrm{~m}^{3} \mathrm{~m}^{-3}$ \\
\hline$h_{V G}$ & 0.10 & -0.28 & -0.73 & -0.19 & -0.40 & -0.43 & - \\
\hline $\mathrm{n}_{\mathrm{VG}}$ & 1.24 & 1.33 & 1.21 & 1.17 & 1.19 & 1.37 & - \\
\hline $\mathrm{K}_{\text {sat }}$ & $2.8 \times 10^{-8}$ & $5.7 \times 10^{-7}$ & $5.0 \times 10^{-7}$ & $4.7 \times 10^{-7}$ & $3.4 \times 10^{-7}$ & $6.3 \times 10^{-8}$ & $\mathrm{~ms}^{-1}$ \\
\hline$a_{\text {Elim }}$ & 21 & 12 & 35 & 21 & 45 & 26 & - \\
\hline$b_{\text {Elim }}$ & 4 & 2 & 29 & 30 & 37 & 31 & - \\
\hline $\mathrm{f}_{\text {therm }}$ & 3.17 & 2.34 & 2.01 & 4.01 & 4.49 & 4.82 & - \\
\hline $\mathrm{d}_{\mathrm{g} 1}$ & 0.5 & 0.1 & 0.1 & 0.06 & 0.1 & 0.1 & $\mathrm{~m}$ \\
\hline $\mathrm{d}_{\mathrm{g} 2}$ & 1.3 & 1.1 & 1.8 & 1.6 & 1.3 & 1.8 & $\mathrm{~m}$ \\
\hline$\Delta \mathrm{w}_{\mathrm{g} 1,0}$ & -0.02 & -0.02 & 0.00 & -0.02 & -0.02 & 0.00 & $\mathrm{~m}^{3} \mathrm{~m}^{-3}$ \\
\hline$\Delta \mathrm{w}_{\mathrm{g} 2,0}$ & -0.01 & -0.02 & 0.01 & 0.02 & 0.00 & 0.02 & $\mathrm{~m}^{3} \mathrm{~m}^{-3}$ \\
\hline$\Delta \mathrm{T}_{\mathrm{g} 2,0}$ & -0.7 & -1.9 & 1.3 & 0.5 & -1.0 & -0.6 & $\mathrm{~K}$ \\
\hline
\end{tabular}



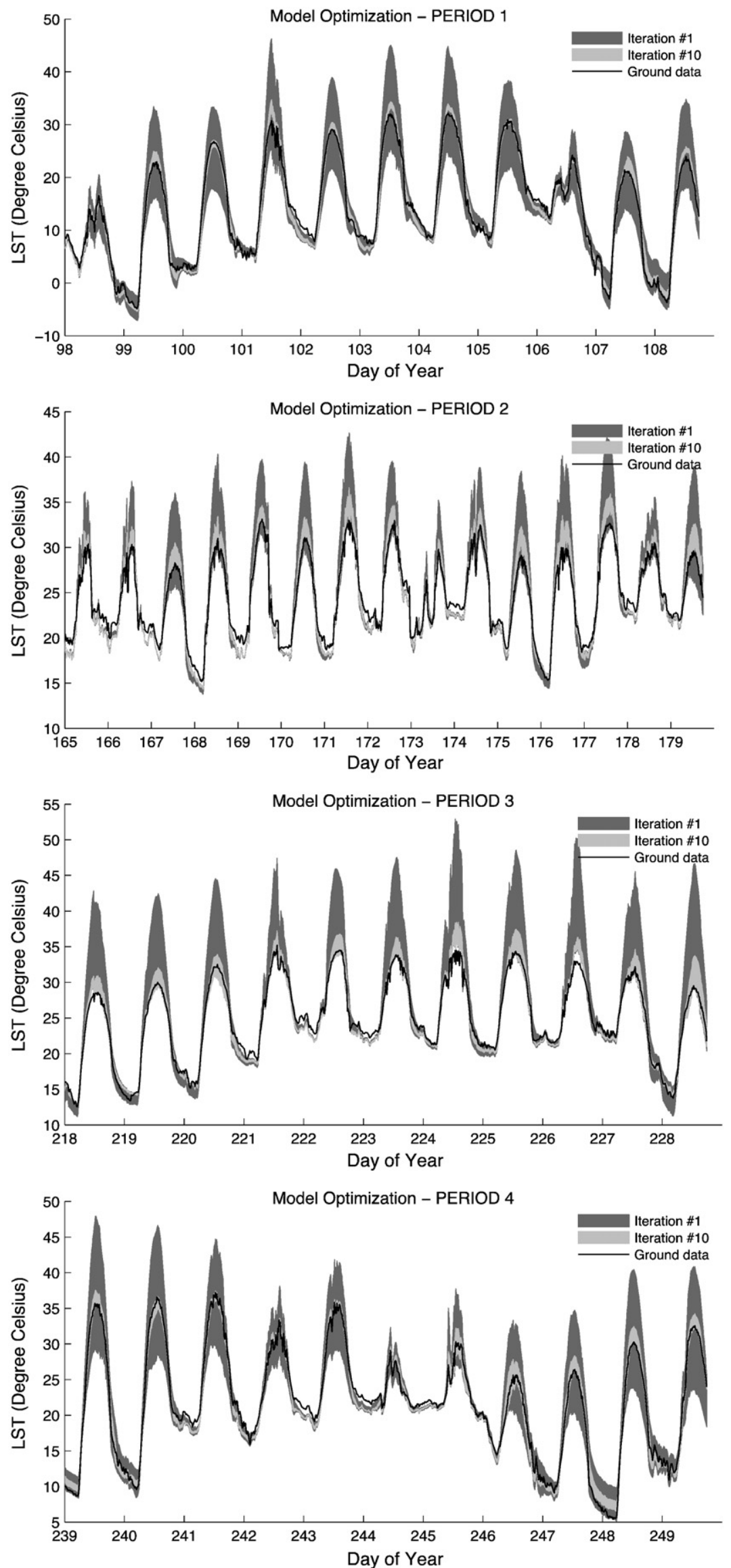

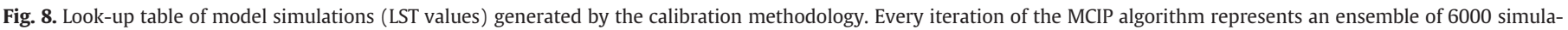
tions. Ten iterations are used to minimize the bias $(\approx 0 \mathrm{~K})$ and RMSE $(<1 \mathrm{~K})$ between observed (black line) and simulated LST. 

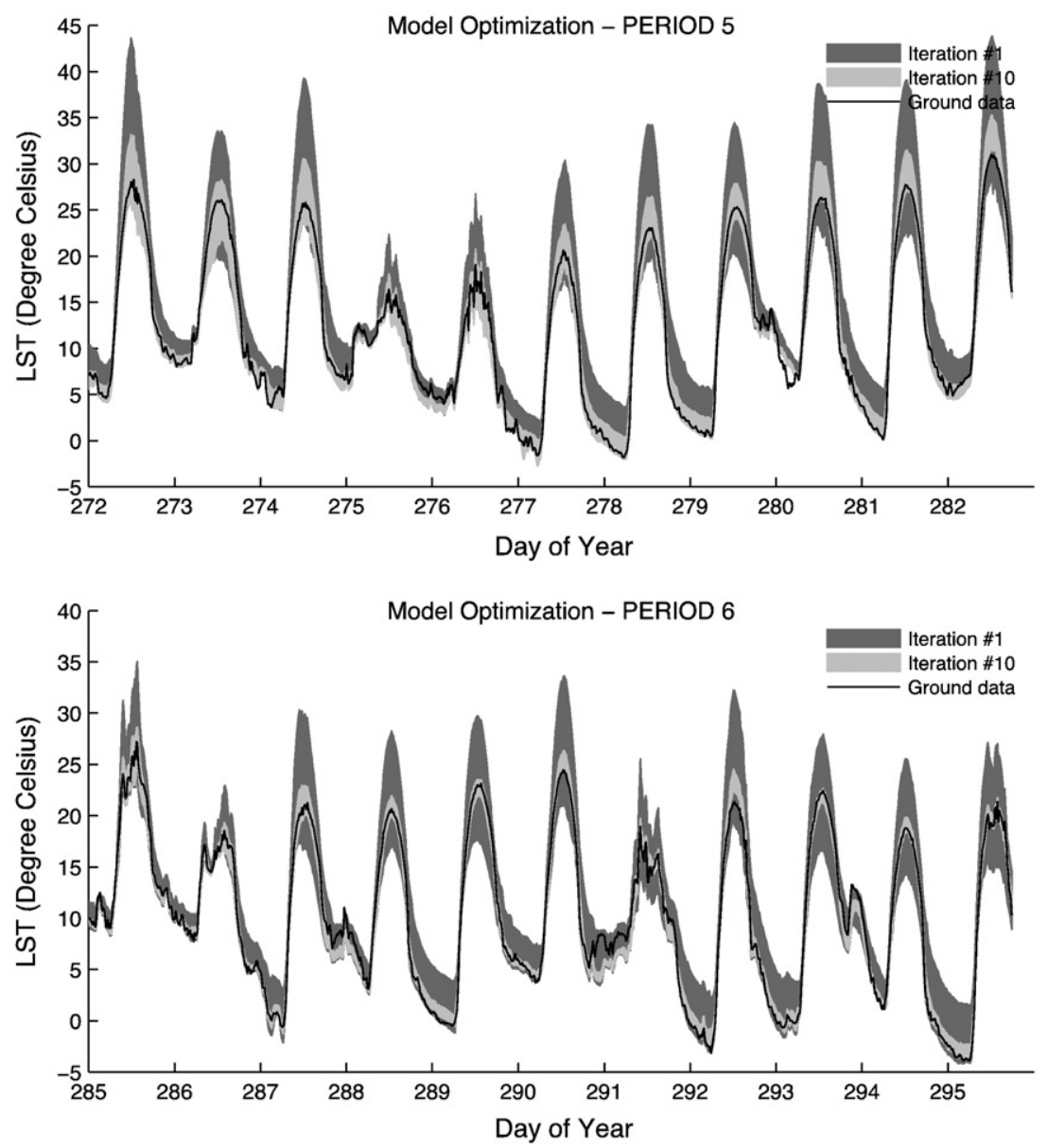

Fig. 8 (continued).

days and good quality satellite data (Table 3 ). The bit flags provided with MODIS LST products (Wan, 2008) describe the quality assurance associated with the product. In the study, we have only used "good quality" products (mandatory quality assurance flag $=00$ ), which do not require additional and detailed quality assurance (Wan, 2008). We have not specified any restriction on the sensor viewing zenith angle. Each period represents ten or more consecutive days, for which at least ten "clear sky" MODIS data are available. In the study, we have used a total of 113 MODIS scenes collected over 64 days in 2010 (Table 3).

\subsection{Vegetation density maps from MODIS NDVI products}

Four years of MODIS data (from 2007 to 2010) at $1 \mathrm{~km}$-spatial and 15 days-temporal resolutions are used to characterize the relationship between the NDVI and the LAI (Fig. 6). The three empirical parameters of Eq. (4) are estimated using the simplex method to minimize the RMSE between measured and estimated LAI values at $1 \mathrm{~km}$ resolution. The initial set of parameters used by the simplex method is defined by Courault et al. (2010) for a permanent grassland: initial values of $\mathrm{K}_{\mathrm{LAI}}$, $\mathrm{NDVI}_{\propto}$ and $\mathrm{NDVI}_{\mathrm{S}}$ are $0.71,0.89$ and 0.1 , respectively. After optimization, the three parameters, i.e. $\mathrm{K}_{\mathrm{LAI}}, \mathrm{NDVI}_{\propto}$ and $\mathrm{NDVI}_{\mathrm{s}}$ are assessed at $1.05,0.91$ and 0.14 , respectively, and the RMSE between measured and estimated $1 \mathrm{~km}$ LAI is $0.28 \mathrm{~m}^{2} \mathrm{~m}^{-2}$. Then, we have applied the relationship calibrated at $1 \mathrm{~km}$ resolution to MODIS NDVI data at $250 \mathrm{~m}$ resolution and we have derived LAI values at $250 \mathrm{~m}$ resolution. Observed variations in LAI of the 16 MODIS $250 \mathrm{~m}$ subpixels located around the ground station and included in the MODIS LST pixel are represented in Fig. 6. The subpixel corresponding to the location of the station is represented in bold gray, and the averaged LAI calculated over the 16 subpixels is in good agreement with MODIS LAI standardproduct at $1 \mathrm{~km}$. In comparison with MODIS LAI at $1 \mathrm{~km}$, the field site LAI is lower during summer time when the surrounding crops are

Table 5

Bias, standard deviation of the difference (STD) and root mean square error (RMSE) calculated between MODIS LST products at $1 \mathrm{~km}$ resolution and ground-based LST with and without scaling. Results over whole validation periods, daytime and nighttime periods are represented. Results for all periods are in bold.

\begin{tabular}{|c|c|c|c|c|c|c|c|}
\hline \multirow[t]{2}{*}{ Period } & & \multicolumn{3}{|c|}{$\begin{array}{l}\text { Satellite vs. non scaled } \\
\text { LST }\end{array}$} & \multicolumn{3}{|c|}{$\begin{array}{l}\text { Satellite vs. scaled-up } \\
\text { LST }\end{array}$} \\
\hline & & Bias & STD & RMSE & Bias & STD & RMSE \\
\hline \multirow[t]{3}{*}{1} & All & -1.1 & 3.9 & 4.0 & -0.4 & 3.1 & 3.1 \\
\hline & Daytime & -5.5 & 1.9 & 5.8 & -3.8 & 1.9 & 4.2 \\
\hline & Nighttime & 1.8 & 1.0 & 2.0 & 1.8 & 0.9 & 2.0 \\
\hline \multirow[t]{3}{*}{2} & All & 0.2 & 1.1 & 1.0 & 0.3 & 1.1 & 1.1 \\
\hline & Daytime & 0.2 & 0.9 & 0.9 & 0.4 & 0.9 & 1.0 \\
\hline & Nighttime & 0.2 & 1.7 & 1.4 & 0.2 & 1.7 & 1.4 \\
\hline \multirow[t]{3}{*}{3} & All & 1.6 & 1.9 & 2.4 & 0.6 & 1.6 & 1.7 \\
\hline & Daytime & 2.4 & 1.6 & 2.9 & 1.2 & 1.6 & 1.9 \\
\hline & Nighttime & -0.4 & 0.9 & 0.9 & -0.7 & 1.0 & 1.1 \\
\hline \multirow[t]{3}{*}{4} & All & 1.3 & 2.5 & 2.8 & 0.4 & 1.9 & 1.9 \\
\hline & Daytime & 2.9 & 1.8 & 3.4 & 1.6 & 1.5 & 2.1 \\
\hline & Nighttime & -1.1 & 1.0 & 1.5 & -1.2 & 1.0 & 1.5 \\
\hline \multirow[t]{3}{*}{5} & All & -1.4 & 2.8 & 3.1 & -0.4 & 1.9 & 1.9 \\
\hline & Daytime & -3.9 & 1.5 & 4.1 & -1.6 & 1.2 & 2.0 \\
\hline & Nighttime & 0.8 & 1.6 & 1.8 & 0.7 & 1.7 & 1.8 \\
\hline \multirow[t]{3}{*}{6} & All & -0.3 & 2.1 & 2.0 & 0.1 & 1.5 & 1.4 \\
\hline & Daytime & -2.5 & 1.2 & 2.8 & -1.2 & 1.1 & 1.6 \\
\hline & Nighttime & 1.0 & 1.1 & 1.4 & 0.8 & 1.1 & 1.4 \\
\hline \multirow[t]{3}{*}{ All periods } & All & -0.3 & 3.0 & 3.0 & 0.0 & 2.0 & 2.0 \\
\hline & Daytime & -1.3 & 3.5 & 3.7 & -0.7 & 2.3 & 2.4 \\
\hline & Nighttime & 0.7 & 1.5 & 1.7 & 0.6 & 1.5 & 1.7 \\
\hline
\end{tabular}



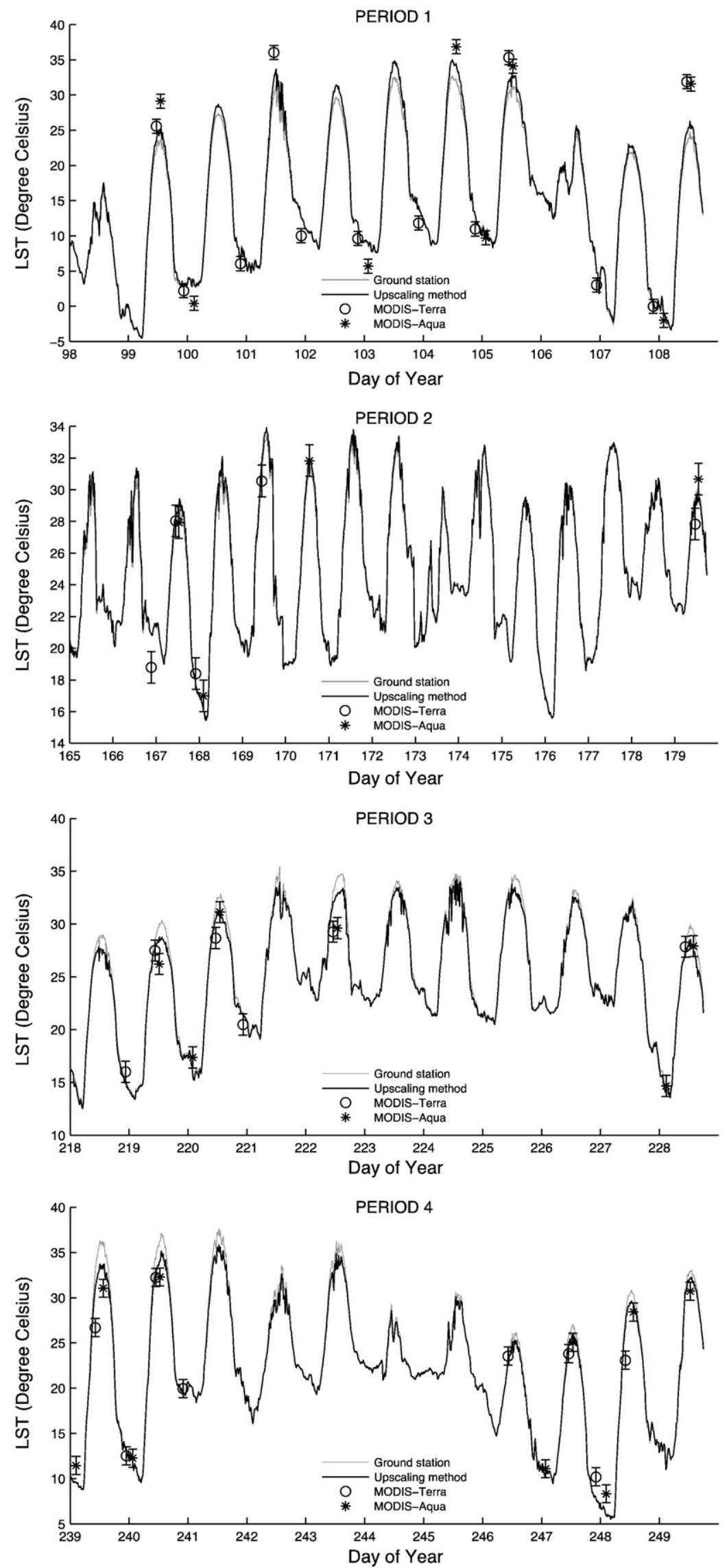

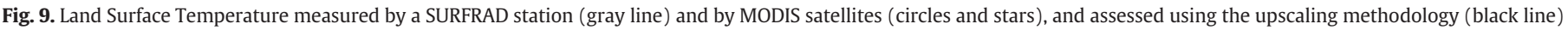

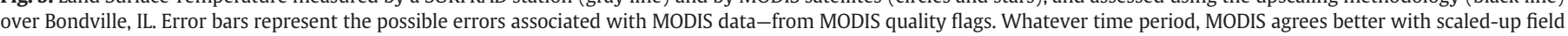
data than with non-scaled field observations. 

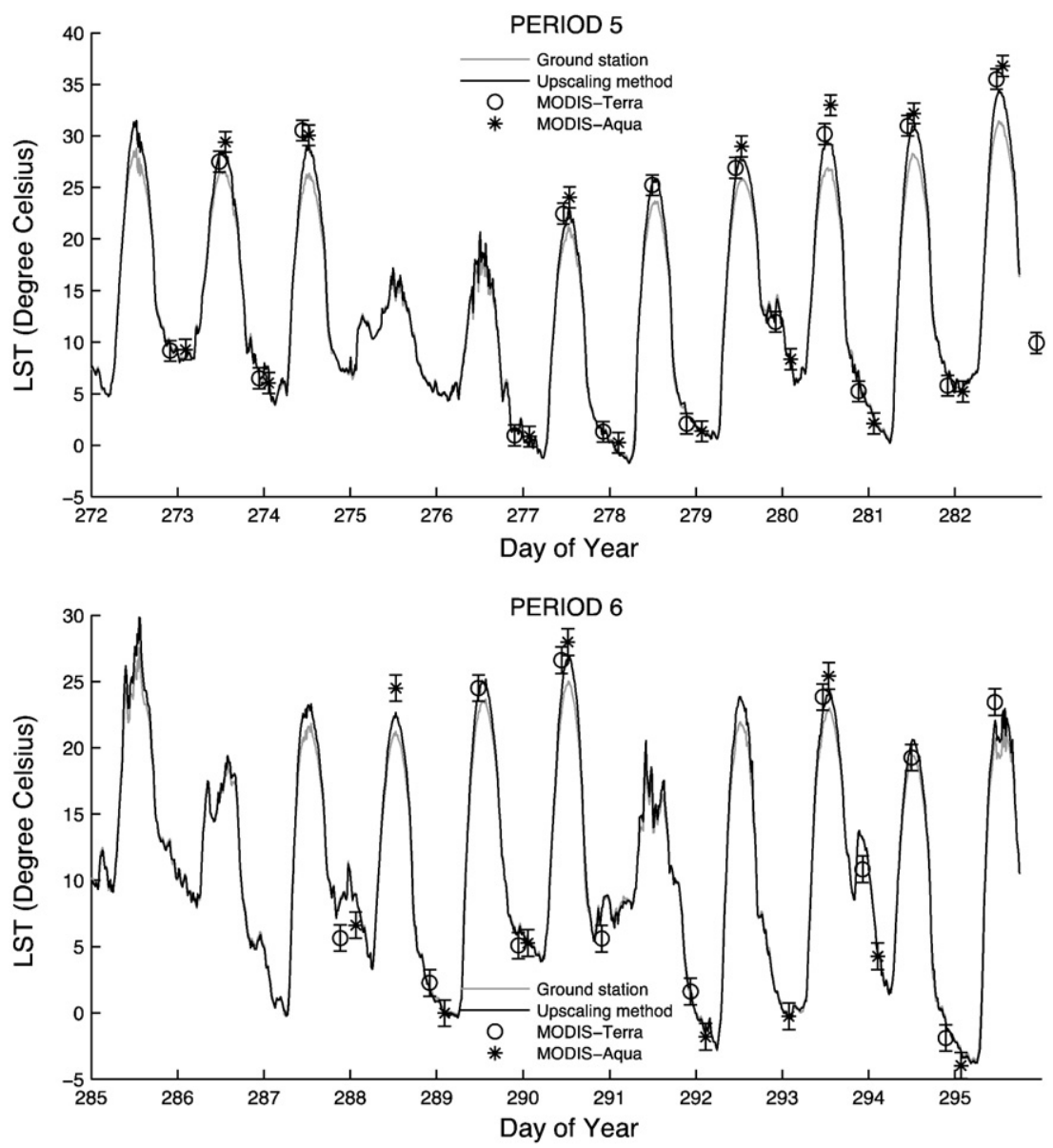

Fig. 9 (continued).

well developed, and is higher after harvesting, i.e. when the grassland is mainly surrounded by bare soil. Due to such seasonal variations in vegetation density around the station, MODIS LST products are in general lower (up to $5 \mathrm{~K}$ around solar noon) than the ground-based LST during the summer months and higher (up to $6 \mathrm{~K}$ around solar noon) after harvesting (mid-September). The 15-day temporal resolution of NDVI/ LAI MODIS data is not appropriate to account for fast change in vegetation densities in the validation scheme. Thus, we have excluded periods around the harvest dates (around mid-September 2010), which are between period 4 and period 5. (Table 3).Model calibration and sensitivity study.

The calibration of the SETHYS model represents the adjustment of the model's unknown parameters while using all available information to describe the ground-based LST, i.e., the atmospheric forcing collected by the station and the LAI derived from MODIS NDVI products at $250 \mathrm{~m}$ resolution corresponding to the location of the station. The model is calibrated over the six selected validation periods (Table 3), by adjusting twenty-three model parameters using the iterative MCIP algorithm. The initial parameter range (Table 2) is defined using commonly used surface properties values (Coudert et al., 2006; Sellers et al., 1992, 1996b). Soil moisture and soil temperature profile measurements made at the USCRN station are used to define model initial conditions. Ten algorithm iterations are processed to reduce the parameter ranges and minimize two predefined cost functions (Fig. 7): the bias and RMSE calculated for every period between simulated and ground-based LST. The ground-based LST used to adjust the SETHYS model is derived from SURFRAD data using Eq. (3) after resampling the observed data at 15 -minute resolution-that represents the model time step. Our validation site represents an evergreen grassland, for which the broadband surface emissivity is constant in time and equal to 0.975 (Yu et al., 2010). Yu et al., (2010) used narrowband emissivity values from the Cooperative Institute for Meteorological Satellite Studies (CIMSS) Global Infrared Land Surface Emissivity Database (Seemann et al., 2008) and a regression from Wang et al. (2005) to estimate broadband emissivity values over station locations. Then, statistics used by the MCIP algorithm are processed using 1056 samples for every period: 11-day periods at $15 \mathrm{~min}$ time step. As defined by Coudert et al. (2006) and Saux-Picart et al. (2009a), every iteration represents an ensemble of 6000 simulations generated by sampling parameter uncertainty ranges. However, for all the periods, no significant gain is observed after 7 iterations (Fig. 7), and the absolute value of the bias, the RMSE and correlation coefficient calculated between observed and simulated LST are typically lower than $0.5 \mathrm{~K}$, lower than $1.5 \mathrm{~K}$ and higher than 0.99 , respectively for each of the 6000 simulations (Fig. 7).

During the calibration phase, the model is only constrained by ground station LST, as LST is the only model output that can be derived from both CRN and SURFRAD data, and that is quality-controlled by NOAA. However, as discussed by Demarty et al. (2005), a more efficient calibration would require surface flux measurements to consistently adjust both energy and water exchanges represented by the model. Also, we have chosen to calibrate the model over every selected validation periods to optimize the model performance and minimize the possible impact of using a single variable during the calibration. As a result, parameter values obtained after calibration are time-period dependent, and may vary from one calibration/validation period to another (Table 4). Furthermore, optimal parameters associated with a specific period allow to compensate for discrepancies induced by model parameterization and/or input data uncertainties related to the considered time period, e.g., LAI and atmospheric forcing. 
Results show that parameters related to the calculation of the surface net radiation, e.g. soil and vegetation optical properties (see Table 2 for parameter description), are very sensitive, i.e. they converge towards an optimal value after few iterations, and final calibrated values are more consistent through various periods of time. Besides, parameters related to surface evapotranspiration are sensitive but strongly dependent on the validation periods or seasons: parameters describing soil evaporation have a more significant influence on LST when the vegetation density is relatively low (periods 1,5 and 6) than during the summer months when the LAI is higher (periods 2, 3 and 4). As expected, we find an opposite impact on results-parameter more sensitive when the vegetation is more active-when considering parameters characterizing vegetation processes, e.g., the leaf photosynthetic capacity $\left(\mathrm{V}_{\max }\right)$ that represents the leaf maximum photosynthetic rate and indirectly regulates vegetation transpiration through the stomatal conductance.

For most of the validation periods, the ground-based LST is included in the look-up table of simulations (Fig. 8). For periods 2 and 3, even if the MCIP algorithm is able to provide an acceptable solution, the model globally overestimates the LST compared to the ground measurements. However, such differences have no significant impact on scaled-up LST values, which calculation is based on the absolute in-situ LST and differences between simulated LST values (Eq. 1). For each validation period, the absolute value of the bias and the RMSE of in-situ LST and the "best" simulated LST after calibration, i.e., from the simulation with the lowest RMSE after 10 iterations, are lower than $0.4 \mathrm{~K}$ and $1.0 \mathrm{~K}$, respectively.

\subsection{Comparisons with satellite-derived LST}

A collection of 113 MODIS clear-sky images collected during 2010 (Table 3) were used to evaluate the scaling methodology by comparing satellite-derived data with ground-based LST accounting for and without scaling process (Table 5; Figs. 9 and 10). Whichever validation period, MODIS LST products agree better with scaled-up field data than with non-scaled field observations. Globally, over all the periods, the scaled-up field data are more comparable with satellite products: the standard deviation of the difference between satellite LST and ground-based data-that represents the precision of the satellite product-is about $2 \mathrm{~K}(2.3 \mathrm{~K}$ when considering daytime observations only) with scaling and $3 \mathrm{~K}$ ( $3.5 \mathrm{~K}$ with daytime observations) without scaling (Table 5). The associated coefficients of determination $\left(\mathrm{r}^{2}\right)$ calculated between satellite-derived and in-situ data are 0.93 without scaling and 0.96 with scaling (Fig. 10). When considering nighttime data only, the scaling process does not provide a significant gain, and the precision associated with the product is around $1.6 \mathrm{~K}$ with or without accounting for scaling process. This can be explained by the fact that at night, less energy is exchanged between the surface and the atmosphere. The primary surface fluxes that explain temperature spatial variabilities wich are directly related to land covers distribution, such as shortwave radiation budget or evapotranspiration, drop to zero or are less significant at nighttime. Then, the LST distribution within a satellite pixel appears more homogeneous. As a result, scaling processes have a less significant impact on the integrated LST during nighttime periods.

Except for period 1, the RMSE calculated between MODIS LST and scaled-up ground data is lower than $2 \mathrm{~K}$ when calculated over the 5 other 11-day periods, and typically higher than $2 \mathrm{~K}$ and up to $3.1 \mathrm{~K}$ without scaling. For period 1 , even if the scaling methodology provides more reliable information for comparison with the satellite, we find significant discrepancies between satellite and ground-based measurements: RMSE around $3.1 \mathrm{~K}$ with scaling and around $4.0 \mathrm{~K}$ without scaling-up. Such a result could illustrate one limitation of our methodology, and the fact that the quality of model inputs can strongly influence final results. For period 1, defined from April 8 (day of year 98) to April 18 (day of year 108), the LAI derived from MODIS NDVI and directly used as model input is lower than 0.5 during the 11-day period. Such a value seems relatively low for a grassland that has been mowed for the last time in October of the previous year. We believe that in that case-more noticeable because the LAI of the surrounding area is very low at this time of the yearthe $250 \mathrm{~m}$ MODIS NDVI could be underestimated by the fact that the satellite pixel can integrate information not only related to the field where the station is located but also information related to the surrounding area, i.e. bare soil in our case.

Except for period 1, we have found a very consistent match between satellite and scaled-up field data (Fig. 9). When the LAI of the pixel corresponding to the location of the station is lower than (periods 3 and 4), similar to (period 2) or higher than (periods 5 and 6) the averaged LAI of the surrounding area (i.e., $1 \mathrm{~km}$ pixel), the approach logically provides scaled-up LST values that are lower than, similar to or higher than the observed in situ LST, respectively. Moreover, MODIS measured similar behavior and the derived LST products are very consistent with the scaled-up data over every validation period. In comparison with
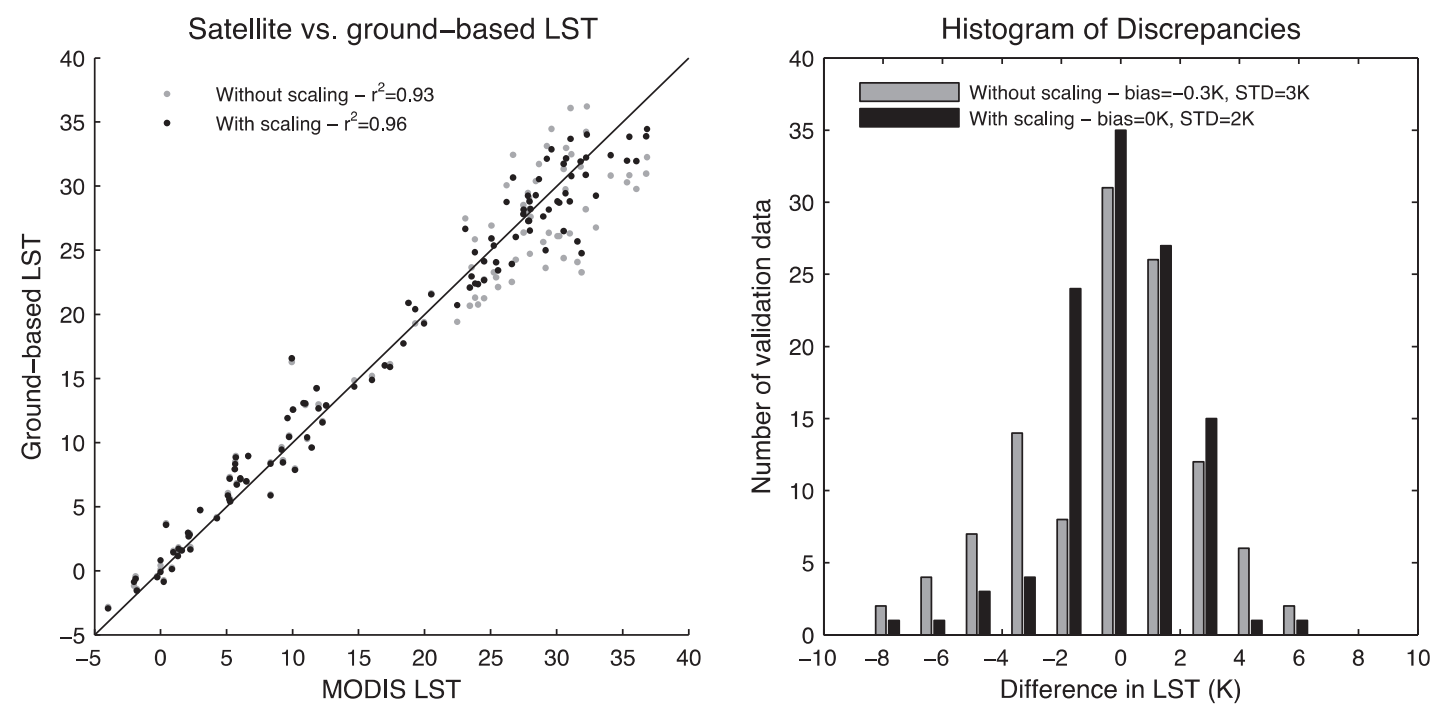

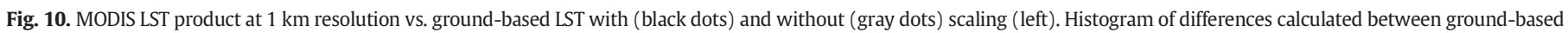
LST with (black dots) and without (gray dots) scaling and MODIS LST products (right). 
ground-based LST, low LST values retrieved from both MODIS Aqua and Terra sensors on day of year 222 or from Aqua on day 219 are difficult to explain, and could be associated with subpixel clouds contamination.

\section{Discussion}

This work, initiated by the National Polar-orbiting Operational Environmental Satellite System (NPOESS)/JPSS program, is tested and proven here with MODIS data, and it is readily adaptable to some other satellite LST products at moderate resolution. Nevertheless, it makes sense to take a few precautions. We assumed that the atmospheric forcing is uniform over the satellite footprint. The latter assumption is justified over a $1 \times 1 \mathrm{~km}^{2}$ flat area, but becomes more questionable when the spatial resolution decreases. This assumption should be discussed when using coarser resolution data, such as geostationary satellite data with spatial resolution around $3 \mathrm{~km}$ for instance.

Globally, the level of uncertainty of the upscaling methodology is dependent on the quality of the ancillary data used to describe the spatial variability of model input parameters within a 1-km pixel. Here, for the Bondville site, we assume that the atmospheric forcing measured by a station, and the surface properties derived from the SETHYS model calibration process do not vary for each sub-pixel around the station. We suppose that the LST spatial variability is explained by changes in vegetation density that affect the surface energy and water budgets. Then, the surface bulk optical properties (albedo and emissivity), the fraction of Absorbed Photosynthetic Active Radiation (APAR), and the surface fluxes are calculated by the model for each sub-pixel using LAI values retrieved from remote sensing data (MODIS 250 m-NDVI, here). However, specific information derived from the model calibration process, e.g. soil emissivity, soil albedo for wet and dry conditions, single scattering albedo of leaves are considered constant within a $1-\mathrm{km}$ pixel. Such an assumption cannot be easily verified at coarse resolution, but seems to be acceptable for validation sites that are relatively flat and not characterized by a strong variability in terms of surface types, e.g. tree and short vegetation canopies. Accounting for a high resolution land cover classification should improve the scaling methodology and reduce the induced errors on up-scaled LST for sites more heterogeneous. MODIS LST products have already been validated over various land surfaces and climates (see section Introduction for a list of references), and can be considered as a valuable reference at moderate spatial resolution. Therefore, the comparison between up-scaled LST and MODIS LST products represents a first estimate of the errors associated with the scaling methodology. The global uncertainty (accounting for bias and precision) in the up-scaled LST-characterized here by the RMSE between up-scaled and MODIS LSTs-is lower than $2 \mathrm{~K}$ for five of the six time periods we considered. The description of vegetation density variability within a $1-\mathrm{km}$ pixel could be improved by using higher resolution data, such as NDVI products from Landsat or ASTER scenes. However, such high-resolution data will bring new limitations regarding the temporal resolution, because only few ASTER/Landsat scenes are available over specific sites per year. Nevertheless, we will evaluate in further work the capability to use multisensor/resolution data and a disaggregation technique for routine validation, to take advantage of both higher temporal and spatial resolutions.

The routine VIIRS LST validation will mainly be based on ground data from the USCRN network which represents around 120 stations over the continental US. The validation will be done using VIIRS swath granules and the upscaling methodology will account for the system's point spread function. USCRN stations do not measure the incoming longwave radiation that is required by the SETHYS model, and we will use the air temperature and air water vapor content measured at $2 \mathrm{~m}$ height by the USCRN stations to derive such a quantity (Brutsaert, 1975; Idso, 1981).
Errors in LST products derived from satellites arise primarily from various sources such unmasked thin clouds, water vapor content in the atmosphere and uncertainties on surface emissivity. During the NPP extensive validation period, we will evaluate the impact of the atmospheric water vapor on the LST retrieval over our selected validation sites. For that purpose, temperature and water content atmospheric profiles from National Centers for Environmental Prediction (NCEP) will be used with a radiative transfer model to simulate the Top Of Atmosphere (TOA) brightness temperature or Sensor Data Record (SDR), and then characterize the contribution of the atmosphere. When significant discrepancies between the satellite and the ground-based LST are found, the radiance-based comparison allows us to fully characterize the algorithm and will be helpful to provide useful information and guidance to the Algorithm Working Group for algorithm improvement. Ultimately, this may result in the tailoring of LST products with the high level of required data characteristics essential to support weather forecast and climate studies.

\section{Conclusions}

Users of satellite products put a high priority on providing statements of products accuracy-and a product will be used only if it is reliable and therefore fully validated. In this context, we have developed a new validation methodology to monitor the quality of satellite LST products in terms of accuracy and precision at moderate spatial resolution and evaluate retrieval algorithms performance. We demonstrate the difficulty in validating LST products from satellites using in situ measurements over relatively heterogeneous land surface such as agricultural landscapes, and we show the need to account for land cover variability and to scale-up ground-based data to the effective LST measured by the satellite. Since the LST is determined by the energy and water exchanges between the soil, the vegetation and the atmosphere, the present methodology is based on the SETHYS land surface model, which explicitly represents and aggregates the physical processes from ground truth to satellite product resolution. The first results obtained over Bondville, IL (USA) using MODIS products as proxy, are very encouraging for future validation of NPP/VIIRS LST EDR. Using ground-based data without scaling, the accuracy and precision of MODIS LST products-used here as VIIRS proxy-are $-0.3 \mathrm{~K}$ and $3.0 \mathrm{~K}$, respectively. Such precision value does not verify NPP/VIIRS specifications ( $1.5 \mathrm{~K}$ accuracy and $2.5 \mathrm{~K}$ precision). However, the product accuracy and precision calculated using scaledup ground data are around $0 \mathrm{~K}$ and $2 \mathrm{~K}$, respectively, and lower than VIIRS requirements. The routine VIIRS LST validation will be mainly based on ground data from the USCRN network that represents around 120 stations over the continental US.

The final objective of this study is to fully assess the performance of the retrieval LST algorithm and to establish in quasi real time (few hours or days after processing the product) the uncertainties of the VIIRS LST standard-data products for the algorithm-working group and the science-user community. Moreover, to facilitate the production of longer-term data records that will be developed using multiple instruments, e.g. NOAA's Advanced Very High Resolution Radiometer (AVHRR), MODIS and JPSS VIIRS, uncertainties in LST retrieval must be established.

\section{Acknowledgments}

This work is funded by the NPOESS/JPSS program. The MODIS data used in this study are distributed by the Land Processes Distributed Active Archive Center (LPDAAC), located at USGS/EROS, Sioux Falls, SD, http:// lpdaac.usgs.gov. The authors use the Earth Observing System ClearingHOuse (ECHO)/Warehouse Inventory Search Tool (WIST) interface developed by the Earth Observing System Data and Information System (EOSDIS), NASA Goddard Space Flight Center (GSFC)-URL: https://wist. echo.nasa.gov/api/. The authors thank Deb Mish and Sara Veasey from 
NOAA/NCDC's graphic team for providing useful graphic support, and Egg Davis from STG Inc., for discussion regarding the USCRN data.

\section{References}

Asrar, G., Fuchs, M. Kanemasu, E. T. \& Hatfield, J. L (1984). Estimating absorbed photosynthetic radiation and leaf area index from spectral reflectance in wheat. Agronomy Journal, 76, 300-306.

Augustine, J. A., DeLuisi, J. J., \& Long, C. N. (2000). SURFRAD-A national surface radiation budget network for atmospheric research. Bulletin of the American Meteorological Society, 81, 2341-2357.

Augustine, J. A., Hodges, G. B., Cornwall, C. R., Michalsky, J. J., \& Medina, C. I. (2005). An update on SURFRAD-The GCOS surface radiation budget network for the continenta United States. Journal of Atmospheric and Oceanic Technology, 22, 1460-1472.

Barnes, W. L., Pagano, T. S., \& Salomonson, V. V. (1998). Prelaunch characteristics of the Moderate Resolution Imaging Spectroradiometer (MODIS) on EOS-AM1. IEEE Transactions on Geoscience and Remote Sensing, 36(4), 1088-1100.

Bastidas, L. A., Gupta, H. V., Sorooshian, S., Shuttleworth, W. J., \& Yang, Z. L. (1999). Sensitivity analysis of a land surface scheme using multicriteria methods. Journal of Geophysical Research, 104, 19481-19490.

Becker, F., \& Li, Z. L. (1990). Towards a local split window method over land surfaces. International Journal of Remote Sensing, 11(3), 369-393.

Bosilovich, M. G. (2006). A comparison of MODIS land surface temperature with in situ observations. Geophysical Research Letters, 33, L20112. http://dx.doi.org/10.1029/ 2006GL027519.

Brutsaert, W. (1975). On a derivable formula for long-wave radiation from clear skies. Water Resources Research, 11(5), 742-744.

Bsaibes, A., Courault, D., Baret, F., Weiss, M., Olioso, A., Jacob, F., et al. (2009). Albedo and LAI estimates from FORMOSAT-2 data for crop monitoring. Remote Sensing of Environment, 113, 716-729.

Chen, W., \& Henebry, G. M. (2009). Change of spatial information under rescaling: A case study using multi-resolution image series. ISPRS Journal of Photogrammetry and Remote Sensing, 64, 592-597.

Coll, C., Wan, Z. M., \& Galve, J. M. (2009). Temperature-based and radiance-based validations of the V5 MODIS land surface temperature product. Journal of Geophysical Research-Atmospheres, 114, D20102. http://dx.doi.org/10.1029/2009JD012038.

Collatz, G., Bounoua, L., Los, S., Randall, D., Fung I., \& Sellers, P. (2000). A mechanism for the influence of vegetation on the response of the diurnal temperature range to changing climate. Geophysical Research Letters, 3381-3384.

Collatz, G., Ribas-Carbo, M., \& Berry, J. (1992). Coupled photosynthesis-stomatal conductance model for leaves of C4 plants. Australian Journal of Plant Physiology, 519-538.

Coudert, B., \& Ottlé, C. (2007). An improved SVAT model calibration strategy based on the optimisation of surface temperature temporal dynamics. Geophysical Research Letters, 34, L04402. http://dx.doi.org/10.1029/2006GL028778.

Coudert, B., Ottlé, C., Boudevillain, B., Demarty, J., \& Guillevic, P. (2006). Contribution of thermal infrared remote sensing data in multiobjective calibration of a dual-source SVAT model. Journal of Hydrometeorology, 7, 404-420.

Coudert, B., Ottlé, C. \& Briottet, X. (2008). Monitoring land surface processes with therma infrared data: Calibration of SVAT parameters based on the optimisation of diurna surface temperature cycling features. Remote Sensing of Environment, 112, 872-887.

Courault, D., Bsaibes, A., Kpemlie, E., Hadria, R., Hagolle, O., Marloie, O., et al. (2008) Assessing the potentialities of FORMOSAT-2 data for water and crop monitoring at small regional scale in South-Eastern France. Sensors, 8, 3460-3481. http://dx.doi.org/ $10.3390 / \mathrm{s} 8053460$

Courault, D., Hadria, R., Ruget, F., Olioso, A, Duchemin, B., Hagolle, O., et al. (2010). Combined use of FORMOSAT-2 images with a crop model for biomass and wate monitoring of permanent grassland in Mediterranean region. Hydrology and Earth System Sciences, 14, 1731-1744.

Deardorff, J. W. (1978). Efficient prediction of ground surface temperature and moisture, with inclusion of a layer of vegetation. Journal of Geophysical Research, 83, 1889-1903.

Demarty, J., Ottlé, C., Braud, I., Olioso, A., Frangi, J. P., Bastisdas, L. A., et al. (2004). Using a multi-objective approach to retrieve information on surface properties used in a SVAT model. Journal of Hydrology, 287, 214-236.

Demarty, J., Ottlé, C., Braud, I., Olioso, A., Gupta, H. V., \& Bastidas, L. A. (2005) Constraining a physically based Soil-Vegetation-Atmosphere Transfer mode with surface water content and thermal infrared brightness temperature measurements using a multi-objective approach. Water Resources Research, 41, W01011. http://dx.doi.org/10.1029/2004WR003695.

Dozier, J., \& Warren, S. G. (1982). Effect of viewing angle on the infrared brightness temperature of snow. Water Resources Research, 18, 1424-1434.

François, C. (2002). The potential of directional radiometric temperatures for monitoring soil and leaf temperature and soil moisture status. Remote Sensing of Environment, 80, 122-133.

Goettsche, F. M., Olesen, F. S., \& Bork-Unkelbach, A. (in press). Validation of land surface temperature derived from MSG/SEVIRI with in-situ measurements at Gobabeb, Namibia. International Journal of Remote Sensing.

Guillevic, P., Gastellu-Etchegorry, J. P., Demarty, J., \& Prevot, L. (2003). Thermal infrared radiative transfer within three-dimensional vegetation covers. Journal of Geophysical Research-Atmospheres, 108, 4248.

Guillevic, P., \& Koster, R. D. (2002). Role of interannual vegetation variability in climate. Bulletin of the American Meteorological Society, 83(12), 1753-1754

Guillevic, P., Koster, R., Suarez, M., Bounoua, L., Collatz, G., Los, S., et al. (2002). Influence of the interannual variability of vegetation on the surface energy balance-A global sensitivity study. Journal of Hydrometeorology, 617-629.
Gupta, H. V., Bastidas, L. A., Sorooshian, S., Shuttleworth, W. J., \& Yang, Z. L. (1999). Parameter estimation of a land surface scheme using multicriteria methods. Journal of Geophysical Research, 104(19), 19491-19503.

Hall, D. K., Box, J. E., Casey, K. A., Hook, S. J., Shuman, C. A., \& Steffen, K. (2008). Comparison of satellite-derived and in-situ observations of ice and snow surface temperatures over Greenland. Remote Sensing of Environment, 112, 3739-3749.

Hook, S. J., Vaughan, R. G., Tonooka, H., \& Schladow, S. G. (2007). Absolute radiometric in-flight validation of mid infrared and thermal infrared data from ASTER and MODIS on the Terra Spacecraft using the Lake Tahoe, CA/NV, USA, automated validation site. IEEE Transactions on Geoscience and Remote Sensing, 45, 1798-1807.

Hulley, G. C. \& Hook, S. J. (2009a). Intercomparison of Versions 4, 4.1 and 5 of the MODIS land surface temperature and emissivity products and validation with laboratory measurements of sand samples from the Namib Desert, Namibia. Remote Sensing of Environment, 133, 1313-1318.

Hulley, G. C., \& Hook, S. J. (2009b). The North American ASTER Land Surface Emissivity Database (NAALSED) Version 2.0. Remote Sensing of Environment, 1967-1975.

Hulley, G. C., \& Hook, S. J. (2010). Generating consistent land surface temperature and emissivity products between ASTER and MODIS data for earth science research. IEEE Transactions on Geoscience and Remote Sensing, 1304-1315. http://dx.doi.org/ 10.1109/TGRS.2010.2063034.

Hulley, G. C., Hook, S. J., Manning, E., Lee, S. -Y., \& Fetzer, E. (2009). Validation of the Atmospheric Infrared Sounder (AIRS) Version 5 land surface emissivity product over the Namib and Kalahari Deserts. Journal of Geophysical Research, 114, D19104.

Idso, S. B. (1981). A set of equations for full spectrum and 8- to 14- $\mu \mathrm{m}$ and 10.5- to 12.5- $\mu \mathrm{m}$ thermal radiation from cloudless skies. Water Resources Research, 17(2), 295-304.

Intsiful, J., \& Kunstmann, H. (2008). Upscaling of land-surface parameters through inverse stochastic SVAT-modelling. Boundary-Layer Meteorology, 129, 137-158.

Jacob, F., Schmugge, T., Olioso, A., French, A. N., Ogawa, K., Petitcolin, F., et al. (2008). Potential of thermal infrared remote sensing for the monitoring of land surfaces. Book Chapter. In S. Liang (Ed.), Advances in Land Remote Sensing: System, Modeling, Inversion and Application. (pp. 243-269) Chapter 10.

Jin, Y., Schaaf, C. B., Woodcock, C. E., Gao, F., Li, X., Strahler, A. H., et al. (2003). Consistency of MODIS surface bidirectional reflectance distribution function and albedo retrievals: 2. Validation. Journal of Geophysical Research, 108(D5), 4159. http://dx.doi.org/ 10.1029/2002JD002804.

Justice, C. O., Vermote, E., Townshend, J. R. G., DeFries, R., Roy, D. R., Hall, D. K., et al. (1998). The Moderate resolution Imaging Spectroradiometer (MODIS): land remote sensing for global change research. IEEE Transactions on Geoscience and Remote Sensing, 36(4), 1228-1249.

Kerr, Y. H., Lagouarde, J. P., Nerry, F., \& Ottlé, C. (2004). Land surface temperature retrieval: Techniques and applications: Case of the AVHRR. In D. A. Quattrochi, \& J. C. Luwall (Eds.), Thermal remote sensing in land surface processes (pp. 33-109). Boca Raton Fl: CRC Press.

Lagouarde, J. -P., Ballans, H., Moreau, P., Guyon, D., \& Coraboeuf, D. (2000). Experimental study of brightness surface temperature angular variations of Maritime Pine (Pinus pinaster) stands. Remote Sensing of Environment, 72, 17-34.

Leduc, S., Diamond, H. J., \& Palecki, M. A. (2009). The United States Climate Reference Network (USCRN) annual report for the fiscal year 2009. NOAA/NESDIS National Climatic Data Center Report. http://www.ncdc.noaa.gov/crn/annual-reports.html

Liang, S. (2000). Numerical experiments on the spatial scaling of land surface albedo and leaf area index. Remote Sensing Reviews, 19, 225-242.

Liu, Y., Hiyama, T., \& Yamaguchi, Y. (2006). Scaling of land surface temperature using satellite data: A case examination on ASTER and MODIS products over a heterogeneous terrain area. Remote Sensing of Environment, 105(2), 115-128, http: //dx.doi.org/10.1016/j.rse.2006.06.012.

Meng, C. L., Li, Z. -L., Zhan, X., Shi, J. C., \& Liu, C. Y. (2009). Land surface temperature data assimilation and its impact on evapotranspiration estimates from the Common Land Model. Water Resources Research, 45, W02421. http://dx.doi.org/ 10.1029/2008WR006971.

Menne, M. J., Williams, C. N., \& Palecki, M. A. (2010). On the reliability of the US surface temperature record. Journal of Geophysical Research - Atmosphere, 115, D11108. http://dx.doi.org/10.1029/2009JD013094.

Moran, M. S., Scott, R. L., Keefer, T. O., Hernandez, M., Nearing, G. S., Emmerich, W. E., et al. (2009). Partitioning evapotranspiration in semiarid grassland and shrubland ecosystems using time series of soil surface temperature. Agricultural and Forest Meteorology, 149, 59-72. http://dx.doi.org/10.1016/j.agrformet.2008.07.004.

Myneni, R. B., Hoffman, S., Knyazikhin, Y., Privette, J. L., Glassy, J., Tian, Y., et al. (2002). Global products of vegetation leaf area and fraction of absorbed PAR from year one of MODIS data. Remote Sensing of Environment, 83(2-Jan), 214-231.

Ottlé, C., Kallel, A., Monteil, G., LeHégarat, S., \& Coudert, B. (2008). Subpixel temperature estimation from low resolution thermal infrared remote sensing. IGARSS 2008 proceedings, Boston, USA.

Philipona, R., Dutton, E., Stoffel, T., Michalsky, J., Reda, I., Stifter, A., et al. (2001). Atmospheric longwave irradiance uncertainty: Pyrgeometers compared to an absolute sky-scanning radiometer, atmospheric emitted radiance interferometer, and radiative transfer model calculations. Journal of Geophysical Research, 106, 28,129-28,141. http://dx.doi.org/ 10.1029/2000JD000196.

Philipona, R., Frohlich, C., Dehne, K., DeLuisi, J., Augustine, J., Dutton, E., et al. (1998). The baseline surface radiation network pyrgeometer round-robin calibration experiment. Journal of Atmospheric and Oceanic Technology, 15, 687-696.

Pinheiro, A. C. T., Mahoney, R., Privette, J. L., \& Tucker, C. J. (2006). Development of a daily long term record of NOAA-14 AVHRR land surface temperature over Africa. Remote Sensing of Environment, 103(2), 153-164.

Pinheiro, A. C. T., Privette, J. L., \& Guillevic, P. (2006). Modeling the observed angular anisotropy of land surface temperature in a savanna. IEEE Transactions on Geoscience and Remote Sensing, 44(4), 1036-1047. 
Prata, A. J. (1993). Land surface temperature derived from the advanced very high resolution radiometer and the along-track scanning radiometer I. Theory. Journal of Geophysical Research, 98, 16689-16702.

Prata, A. J. (1994). Land surface temperatures derived from the advanced very high resolution radiometer and the along-track scanning radiometer: 2. Experimental results and validation of AVHRR algorithms. Journal of Geophysical Research, 99(D6), 13025-13058.

Reichle, R. H., Bosilovich, M. G., Crow, W. T., Koster, R. D., Kumar, S. V., Mahanama, S. P., et al. (2009). Recent advances in land data assimilation at the NASA Global Modeling and Assimilation Office. In S. K. Pard (Ed.), Data Assimilation for Atmospheric, Oceanic and Hydrologic Applications (pp. 407-428). London, United Kingdom: Springer-Verland.

Reichle, R. H., Kumar, S. V., Mahanama, S. P. P., Koster, R. D., \& Liu, Q. (2010). Assimilation of satellite-derived skin temperature observations into land surface models. Journal of Hydrometeorology, 11, 1103-1122. http://dx.doi.org/10.1175/2010JHM1262.1.

Salisbury, J. W., \& D'Aria, D. M. (1992). Emissivity of terrestrial materials in the 8-14 $\mu \mathrm{m}$ atmospheric window. Remote Sensing of Environment, 42, 83-106.

Salisbury, J. W., D'Aria, D. M., \& Wald, A. E. (1994). Measurements of thermal infrared spectral reflectance of frost, snow, and ice. Journal of Geophysical Research, 99, $24,235-24,240$.

Saux-Picart, S., Ottlé, C., Decharme, B., André, C., Zribi, M., Perrier, A., et al. (2009). Water and energy budgets simulation over the AMMA-Niger super-site spatially constrained with remote sensing data. Journal of Hydrology, 287-295.

Saux-Picart, S., Ottlé, C., Perrier, A., Decharme, B., Coudert, B., Zribi, M., et al. (2009). SEtHyS_Savannah: A multiple source land surface model applied to Sahelian landscapes. Agricultural and Forest Meteorology, 149, 1421-1432.

Seemann, S. W., Borbas, E. E., Knuteson, R. O., Stephenson, G. R., \& Huang, H. -L. (2008). Development of a global infrared land surface emissivity database for application to clear sky sounding retrievals from multi-spectral satellite radiance measurements. Journal of Applied Meteorology and Climatology, 47, 108-123.

Sellers, P., Berry, J. A., Collatz, G. J., Field, C., \& Hall, F. (1992). Canopy reflectance, photosynthesis, and transpiration. III. A reanalysis using improved leaf models and a new canopy integration scheme. Remote Sensing of Environment, 42, 187-216.

Sellers, P., Los, S., Tucker, C., Justice, C., Dazlich, D., Collatz, G. J., et al. (1996). A revised land surface parameterization (SiB2) for atmospheric GCMs. Part 2: The generation of global fields of terrestrial biophysical parameters from satellite data. Journal of Climate, 9, 706-737.

Sellers, J. P., Randall, D. A., Collatz, G. J., Berry, J. A., Field, C. B., Dazlich, D. A., et al. (1996). A revised land surface parametrization ( $\mathrm{SiB} 2$ ) for atmospheric GCMs. Part I: Model formulation. Journal of Climate, 9, 676-705.

Shukla, J., \& Mintz, Y. (1982). Influence of land-surface evapotranspiration on the earth's climate. Science, 1498-1501.

Snyder, W., \& Wan, Z. (1998). BRDF models to predict spectral reflectance and emissivity in the thermal infrared. IEEE Transactions on Geoscience and Remote Sensing, 36, 214-225.

Sobrino, J. A., Jiménez-Munoz, J. C., \& Verhoef, W. (2005). Canopy directional emissivity: Comparison between models. Remote Sensing of Environment, 99, 304-314.

Sobrino, J. A., \& Romaguera, M. (2004). Land surface temperature retrieval from MSG1-SEVIRI data. Remote Sensing of Environment, 92, 247-254.
Su, W., Charlock, T. P., Rose, F. G., \& Rutan, D. (2007). Photosynthetically active radiation from Clouds and the Earth's Radiant Energy System (CERES) products. Journal of Geophysical Research, 112, G2. http://dx.doi.org/10.1029/2006JG000290.

Thom, A. (1972). Momentum, mass and heat exchange of vegetation. Quarterly Journal of the Royal Meteorological Society, 98, 124-134.

Wan, Z. (2002). Estimate for noise and systematic error in early thermal infrared data of the Moderate Resolution Imaging Spectroradiometer (MODIS). Remote Sensing of Environment, 80, 47-54.

Wan, Z. (2008). New refinements and validation of the MODIS land-surface temperature/emissivity products. Remote Sensing of Environment, 112, 59-74.

Wan, Z., \& Dozier, J. (1989). Land-surface temperature measurement from space: Physical principles and inverse modeling. IEEE Transactions on Geoscience and Remote Sensing 27, 268-278.

Wan, Z., \& Dozier, J. (1996). A generalized split-window algorithm for retrieving land-surface temperature measurement from space. IEEE Transactions on Geoscience and Remote Sensing, 34, 892-905.

Wan, Z., \& Li, Z. L. (2008). Radiance-based validation of the V5 MODIS land-surface temperature product. International Journal of Remote Sensing, 29(17-18), 5373-5395.

Wan, Z., Zhang, Y., Zhang, Q., \& Li, Z. L. (2002). Validation of the land-surface temperature products retrieved from Terra Moderate Resolution Imaging Spectroradiometer data. Remote Sensing of Environment, 83, 163-180.

Wang, K., \& Liang, S. (2009). Evaluation of ASTER and MODIS land surface temperature and emissivity products using long-term surface longwave radiation observations at SURFRAD sites. Remote Sensing of Environment, 113(7), 1556-1565.

Wang, W., Liang, S., \& Meyers, T. P. (2008). Validating MODIS land surface temperature products using long-term nighttime ground measurements. Remote Sensing of Environment, 112, 623-635.

Wang, K., Wan, Z., Wang, P., Sparrow, M., Liu, J., Zhou, X., et al. (2005). Estimation of surface longwave radiation and broadband emissivity using Moderate Resolution Imaging Spectroradiometer (MODIS) land surface temperature/ emissivity products. Journal of Geophysical Research, 110, D11109. http://dx.doi.org/10.1029/2004JD005566.

Wilson, T. B., \& Meyers, T. P. (2007). Determining vegetation indices from solar and photosynthetically active radiation fluxes. Agricultural and Forest Meteorology, 144(3-4), 160-179.

Yu, Y., Privette, J., \& Chen, M. (2010). Validating satellite land surface temperature product using ground data. In J. A. Sobrino (Ed.), 3rd International Symposium on Recent Advances in Quantitative Remote Sensing (pp. 450-455). Valencia, Spain: Valencia University Press.

Yu, Y., Privette, J., \& Pinheiro, A. (2005). Analysis of the NPOESS VIIRS land surface temperature algorithm using MODIS data. IEEE Transactions on Geoscience and Remote Sensing, 2340-2350.

Yu, Y., Tarpley, D., Privette, J. L., Rama, M. K., Raja, V., Vinnikov, K., et al. (2009). Developing algorithm for operational GOES-R land surface temperature product. IEEE Transactions on Geoscience and Remote Sensing, 47(3), 936-951. 